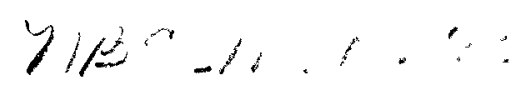

UNITED STATES DEPARTMENT OF COMMERGE • Luther H. Hodges, Secretary NATIONAL BUREAU OF STANDARDS $\bullet$ A. V. Astin, Derector

\title{
An Engineering Method for Calculating Protection Afforded by Structures Against Fallout Radiation
}

Charles Eisenhauer

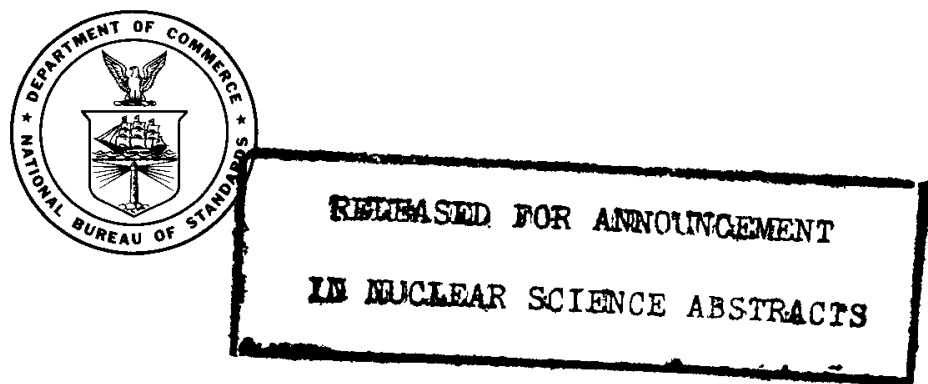

National Bureau of Standards Monograph 76 Issued July 2, 1964 
Library of Congress Catalog Card Number: 64-60024 


\section{DISCLAIMER}

This report was prepared as an account of work sponsored by an agency of the United States Government. Neither the United States Government nor any agency Thereof, nor any of their employees, makes any warranty, express or implied, or assumes any legal liability or responsibility for the accuracy, completeness, or usefulness of any information, apparatus, product, or process disclosed, or represents that its use would not infringe privately owned rights. Reference herein to any specific commercial product, process, or service by trade name, trademark, manufacturer, or otherwise does not necessarily constitute or imply its endorsement, recommendation, or favoring by the United States Government or any agency thereof. The views and opinions of authors expressed herein do not necessarily state or reflect those of the United States Government or any agency thereof. 


\section{DISCLAIMER}

Portions of this document may be illegible in electronic image products. Images are produced from the best available original document. 


\section{Foreword}

The problem of providing protection against the radiations generated by nuclear weapons is of much concern to the Federal Government and to the people of the United States. A great deal of effort and money is being spent currently to analyze existing structures for shielding properties, and plans are being carried forward to design and build shelters of many kinds.

The National Bureau of Standards has maintained a continuing research program directed toward the development of engineering data and methods basic to the solution of these radiation shielding problems. Most of the work of the past few years on this project has been concerned with gamma rays from radioactive fallout. This Monograph discusses the technical basis for the engineering method currently used by the Office of Civil Defense to evaluate fallout protection in structures.

Financial support for this project has come primarily from the Office of Civil Defense, the Defense Atomic Support Agency, both of the Department of Defense, and the Bureau of Yards and Docks, Department of the Navy.

A. V. Astin, Director. 


\section{Contents}

Foreword

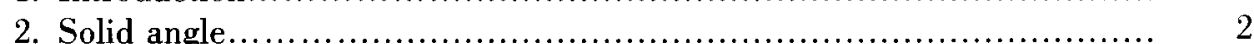

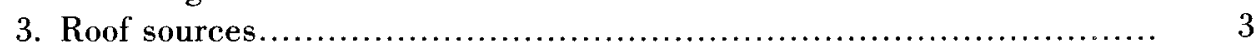

3.1. Schematization............................................... 3

3.2. Angular distributions......................................... 5

4. Ground sources...................................................... 5

4.1. Schematization............................................. 5

4.2. Barrier and geometry factors................................. 6

4.3. Thin-walled structures........................................... 6

4.4. Thick-walled structures.......................................... 8

4.5. Walls of intermediate thickness............................... 10

5. Skyshine ....................................................... 10

6. Limited source areas.................................................. 11

7. Point source......................................................... 12

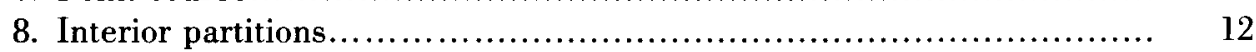

9. Comparison with experiment...................................... 13

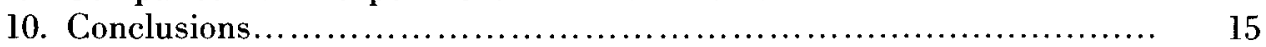

References.......................................................... 15

Bibliography....................................................... 16

Appendix A..................................................... 17

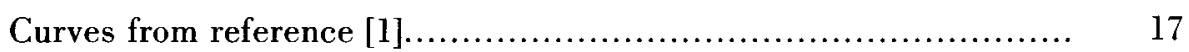

Appendix B......................................................... 18

Charts from Engineering Manual................................. 18 


\title{
An Engineering Method for Calculating Protection Afforded by Structures Against Fallout Radiation
}

\author{
Charles Eisenhauer
}

\begin{abstract}
This report is a discussion of the technical assumptions underlying the methods currently recommended by the Office of Civl Defense (OCD) for calculating protection afforded by structures against fallout radiation. It discusses methods for calculating the contributions from radioactive sources on the roof and on the ground surrounding a simple one-storied building. It shows in detail how each technical chart in the OCD Professional Manual ${ }^{1}$ is derived from basic data on radiation penetration developed by Dr. L. V. Spencer. ${ }^{2}$ Charts from the Professional Manual and relevant curves from Spencer's work are included in this report in order to make it self-contained.
\end{abstract}

\section{Introduction}

A considerable effort has been made in the past few years by the National Bureau of Standards and the Office of Civil Defense to develop engineering rules for calculating the protection afforded by structures against fallout radiation. This effort has resulted in procedures which can be studied at three different levels of complexity.

The primary calculations on the penetration of fallout radiation are reported in an NBS Monograph by L. V. Spencer [1]. ${ }^{3}$ It is written for the physicist or nuclear engineer. It discusses solutions to certain idealized shielding configurations.

Although it indicates how protection in an actual building might be calculated, it does not give any detailed procedures for such calculations. Detailed procedures, based on [1], for calculation of protection afforded by buildings have been developed with the help of Neal FitzSimons of the Office of Civil Defense. These procedures are reported in [2] which has been widely circulated in an Interim Edition and is due to be published shortly. In this paper it will be referred to as the "Engineering Manual". Due to their detailed nature these calculations are often time consuming.

It was therefore necessary to derive a simplified treatment which would be suitable for evaluating protection in a survey of a very large number of buildings. The procedures resulting from this simplified treatment are reported in [3]. Although this treatment retains the essential parameters of the engineering method, it neglects the variation of protection with such parameters as the height above the floor. The protection factors predicted by the simplified method at a fixed height and a central location are assumed to be representative values for a given story of a structure. ${ }^{4}$

This paper will concentrate on the procedures described in the Engineering Manual [2]. The purpose of the paper is to discuss the assumptions and the reasoning by which the calculations described in the Engineering Manual were derived

${ }^{1}$ OCD Professional Manual PM 100-1 Design and Review of Structures for Pro tection from Fallout Gamma Radiation (in press)

${ }_{2} \mathrm{~L} V$ Spencer, Structure Shielding against Fallout Radiation from Nuclear Weap ons, NBS Mono 42, June 1, 1962, US Government Printing Office

${ }^{3} \mathrm{H}$ igures in brackets indicate the literature references on page 15

${ }^{4}$ Under Phase I of the National Fallout Shelter Survey, over 350,000 buldings were evaluated by this simplified treatment [4] from the basic data in [1]. The relevant curves from [1] are given in appendix $A$ and the technical charts from the Engineering Manual are given in appendix $B$. If the reader is interested in the physical principles underlying the basic data he is referred to [1]; if he is interested in applying calculations to actual structures, he is referred to [2].

When referring to basic data, an attempt has been made to preserve the nomenclature used by Spencer [1]. In other cases the notation of the Engineering Manual is used. The notation in equations involving both types of data may therefore be awkward at times.

Schematization has been a basic concept in the development of procedures for calculating the protection afforded by structures against fallout gamma radiation. A schematized configuration is a simplified version of an actual shielding configuration. The configuration is simplified to make it amenable to calculations, but the basic parameters which determine its shielding properties are retained. In practice, the procedure is as follows: First, calculations are made for simple, idealized structures, as a function of parameters such as barrier thickness. Rules are then given for determining these parameters for complex structures. Finally, a complex building is treated by applying the calculations for the simple building having the same set of parameters.

The schematized building considered in the development of the calculations described in this report is shown in figure 1 . It is a cylindrical

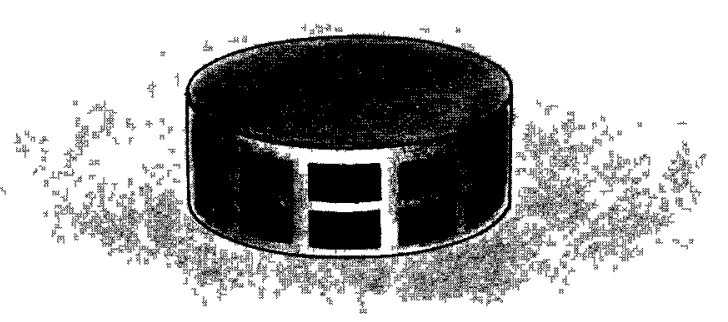

Figure 1. Schematized bullding. 
pillbox, divided into horizontal layers, each of which represents a story of the structure. Since most buildings of interest in shielding are several times longer and wider than an average story height, the radius of the cylinder is several times greater than the height of each layer. Each layer may contain apertures of uniform size and location. This uniformity is apt to be present in upper stories of actual buildings, but not perhaps in the first story. Interactions of gamma rays with the air inside of the building are neglected.

Radiation intensities in structures are calculated in terms of a reduction factor. The reduction factor at any point is the ratio of the exposure dose rate at that point to the exposure dose rate three feet above an infinite plane isotropic source. The source density is assumed to be the same in both cases, and the detectors are assumed to be isotropic, that is, they respond to radiation with equal efficiency in all directions.

A schematized version of the radiation field around a building is shown in figure 2 . The radiation intensity at a detector is assumed to be the sum of three components:

(1) Radiation which arrives at the detector from sources on the roof.

(2) Radiation which reaches the detector from sources on the ground outside. Of the radiation which reaches the wall directly, without scattering in the air, about 75 percent comes from sources which are within $100 \mathrm{ft}$ of the wall. A scale of $100 \mathrm{ft}$ in figure 2 has therefore been indicated as the distance within which sources contribute signifcantly to the direct radiation incident on the wall.

(3) Radiation which arrives at the detector from the upward hemisphere after scattering at least once in the air outside of the building. The contribution to this radiation from a circular annulus of width $\Delta \rho$ at radius $\rho$ from the detector decreases approximately exponentially as $K e^{-\mu}{ }_{0}^{\rho} \Delta \rho$, where $K$ is a constant and $1 / \mu_{0}$ is the mean free path in air. ${ }^{5}$ Since $1 / \mu_{0}$ is of the order of $500 \mathrm{ft}$, this radiation may reach the structure after scattering at any point in air within a hemisphere of radius of roughly $500 \mathrm{ft}$, as indicated in figure 2. This radiation is often referred to as "skyshine".

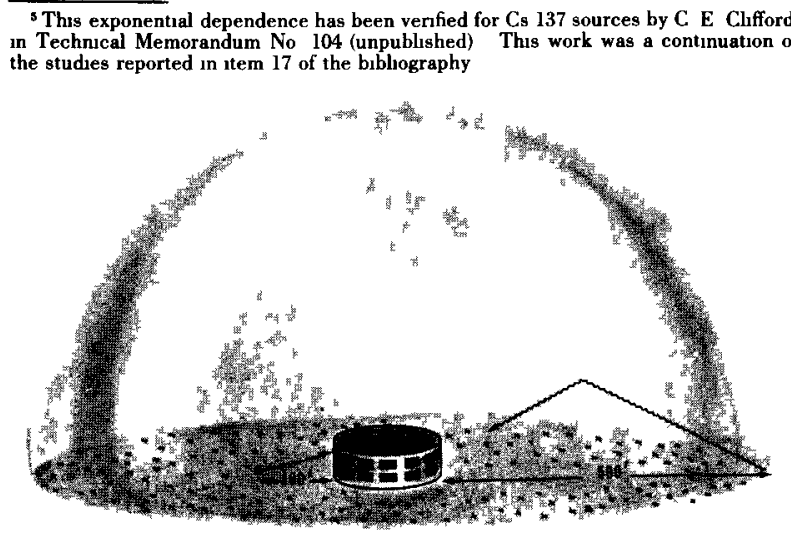

FigURE 2. Types of radiation sources.
Of course, actual buildings and their surroundings are quite different from these schematizations. Some of these schematizations will be justified in the course of this paper. The justification of the others will depend on how useful they are in predicting experimental results on actual buildings.

\section{Solid Angle}

One of the problems in relating actual buildings to schematized buildings is how to relate buildings of different shapes. For example, most of the calculations of [1] apply to circular disk sources, whereas most source areas encountered in practice are rectangular. It is therefore necessary to decide which circular disk calculation should be used, for example, for a given rectangular roof source. One of the first prescriptions which may come to mind is to equate the dose rate from roofs of equal areas. This is a poor technique when applied to gamma radiation, however, because it weights distant source areas too heavily.

A better prescription is to equate surfaces on the basis of the solid angle $\Omega$ subtended at the detector by the surface. As discussed in [1] it is more convenient to work with the solid angle fraction:

$$
\omega=\Omega / 2 \pi .
$$

With this normalization, the solid angle fraction subtended by a plane surface approaches unity as the detector approaches the surface. The solid angle fraction subtended by a plane surface $S$ of arbitrary shape is defined by

$$
\omega=\frac{1}{2 \pi} \int_{S} d(\cos \theta) d \varphi
$$

where $\theta$ is the polar angle relative to a line normal to the plane of the surface and $\varphi$ is the corresponding azimuthal angle. However, the intensity $I$ recorded by a detector which responds with equal efficiency in all directions is given by

$$
I=\int_{S} g(\cos \theta, \varphi) d(\cos \theta) d \varphi
$$

where $g(\cos \theta, \varphi)$ is the angular distribution of radiation flux at the detector, and $S$ is the radiating surface. If the angular distribution at the detector were isotropic $(g=1)$ then the intensity received from rectangular and circular surfaces subtending the same solid angle fraction would be exactly equal. Theory indicates that angular distributions of radiation, plotted against $\cos \theta$ tend to vary from a distribution of $\sim \sec \theta$ which is peaked at $\cos \theta$ $=0$ to a distribution of $\sim \cot \theta$ which is extremely peaked at $\cos \theta=1$. The former is typical of distributions of direct radiation near a plane isotropic source, while the latter is typical of distributions of scattered radiation near a point isotropic source. Most angular distributions will be between these two extremes and therefore will be more 
nearly isotropic. In these cases equating responses from rectangular areas to calculated responses from circular disks subtending the same solid angle fraction will be a fairly good approximation. The solid angle fraction subtended by the circular disk of figure 3 is

$$
\omega=\int_{\cos \theta_{0}}^{1} d(\cos \theta)=1-\cos \theta_{0} \quad \text { (disk) }
$$

A detector inside of a structure is surrounded in general by not one, but at least six rectangular surfaces. It is useful to relate structures of different shape by a minimum number of parameters. In the engineering method the detector response in a rectangular parallelepiped whose ceiling subtends a solid angle fraction of $\omega_{u}$ and whose floor subtends a solid angle fraction of $\omega_{l}$ is equated to a cylindrical story with the same solid angle fractions subtended at the detector, (see fig. 4). This procedure insures that the four walls combined subtend the same solid angle in both structures.

Use of the solid angle fraction as a parameter has the additional advantage that the solid angle fraction subtended by a rectangle can be calculated analytically. It is given by

$$
\omega=\frac{2}{\pi} \tan ^{-1} \frac{e}{n \sqrt{n^{2}+e^{2}+1}} \quad \text { (rectangle) }
$$

where $e$ is the ratio of the half-width of the rectangle to the half-length, and $n$ is the perpendicular distance from the detector to the plane of the rectangle divided by the half-length of the rectangle, (see fig. 5). This expression is plotted as a series of contour curves in figure B3, where the definitions of $n$ and $e$ are equivalent to those in figure 5.

This expression for the solid angle subtended by a rectangle appears in equivalent form in earlier work on thermal radiation [5]. In that context it appears as the angle factor for the heat exchange between a rectangular radiator and a small spherical radiator. It has also appeared in problems in particle detection [6].

\section{Roof Sources}

\subsection{Schematization}

The calculation of radiation dose from roof sources involves two main assumptions. In an actual building there may be several floors and a roof between sources and detector, as shown in figure 6. In general, these floors will be rectangular "plates". In the schematized version the barrier is uniformly distributed between sources and detector with the condition that the total mass thickness between sources and detector be the same in both cases. The rectangular source distribution is replaced by a circular disk source subtending the same solid angle at the detector. These two assumptions will now be considered in greater detail.

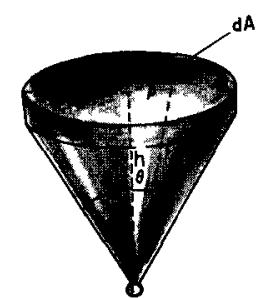

Figure 3. Circular disk radiator.
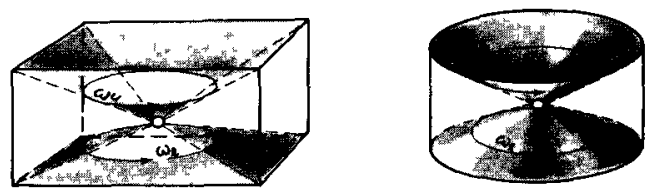

Figure 4. Upper and lower solid angied fractions in a rectangular parallelepiped and a right circular cylinder.

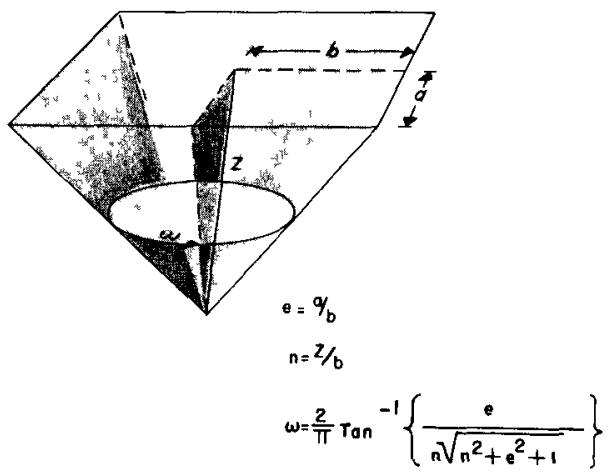

FigURE 5. Solid angle fraction subtended by a rectangle.

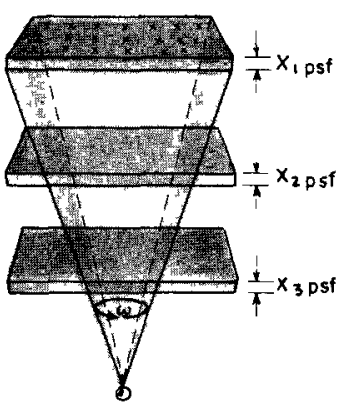

(a)

ACTUAL

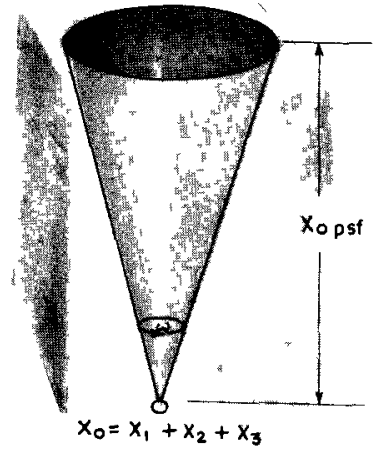

(b)

SCHEMATIZED
FIGURE 6. Relation between an actual configuration and a configuration schematized to compute radiation from roof sources. 
Spencer has calculated three cases relevant to the penetration of roof radiation. The first assumes a circular disk source separated from a detector by a medium uniformly distributed between source and detector. The second assumes the barrier material concentrated at the source. The third assumes the barrier material concentrated at the detector. Since, in most cases, such as the one shown in figure $6 \mathrm{a}$, the barrier is concentrated neither at the source nor the detector, the case of the uniformly distributed barrier was chosen as the closest approximation to cases most commonly occurring in practice.

It is difficult to estimate the error introduced by this approximation. It is expected, however, that the dose rate with several discrete barriers should lie somewhere within the range of dose rates under the three idealized configurations discussed above. The variation in dose rate for three values of the mass thickness $X_{0}$ and the solid angle fraction $\omega$ are shown in each column of table 1 . The values were taken from figures $28.18,28.19$, and 28.20 of [1]. The values for $X_{0} \cong 0$ in table 1 actually apply to $X_{0}=0.22$ pounds per square foot (psf) of concrete which is the equivalent of $3 \mathrm{ft}$ of air. The differences among the three methods at $X_{0} \cong 0$ are due to differences in scattered radiation, and result from the infinite medium sehematization which Spencer used to approximate the three cases, (see page 30 of [1] for further details). From table 1 it can be seen that the variation among the three methods is greatest for thin barriers, amounting to about 40 percent. This would therefore be expected to be the maximum error introduced by approximating a series of discrete barriers by a uniformly distributed barrier equal to their total mass thickness.

An additional error is introduced by the approximation of replacing a rectangular source area by a circular disk. The approximation may be written as

$$
\int_{S} g(\cos \theta) d(\cos \theta) \frac{d \varphi}{2 \pi} \cong \int_{\cos \theta_{0}}^{1} g(\cos \theta) d(\cos \theta)
$$

where $S$ here indicates integration over the rectangle. The value of $\cos \theta_{0}$ on the right-hand side of the equation is determined from the condition that the solid angle fraction subtended by the two surfaces be equal:

$$
\int_{\cos \theta_{0}}^{1} d(\cos \theta)=\int_{S} d(\cos \theta) \frac{d \varphi}{2 \pi}
$$

TABLE 1. - Comparatıve dose rates for three barrier configurations

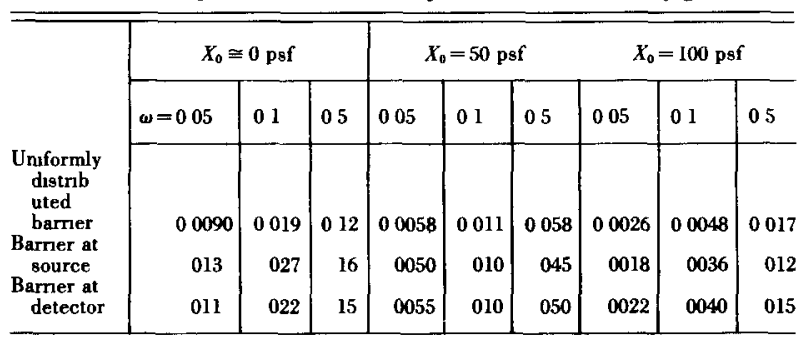
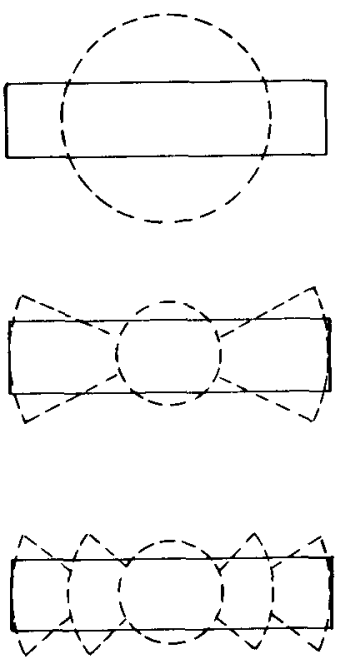

FIGURE 7. Approximation of a rectangle by circular annult.

or

$$
1-\cos \theta_{0}=\omega_{0}
$$

The value of $\omega_{0}$ for the rectangle may be determined from eq (2) of section 2.

The error in dose rate due to approximating a rectangle by a circular disk therefore depends on the form of $g(\cos \theta)$. If the angular distribution is isotropic (i.e., $g(\cos \theta)=1$ ) the condition described by eq (4) implies that eq (3) is exactly true. The maximum error can be estimated by examining two extreme distributions, namely

and

$$
g(\cos \theta)=\sec \theta
$$

$$
g(\cos \theta)=\cot \theta \text {. }
$$

The error in each case can be estimated by successively approximating a rectangle by an increasing number of circular sectors as shown in figure 7 . As the number of circular sections increase the dose rate calculated by the use of circular sectors should approach the true dose rate from the rectangular source. For details of this procedure, see [1].

Dose rates were calculated for the three circularsector approximations shown in figure 7 . The fairly extreme case of a rectangle whose length is five times its width was considered and results were

\begin{tabular}{|c|c|c|c|}
\hline$(e=02)$ & I sector & 2 sectors & 3 sectors \\
\hline $\begin{array}{l}n=02 \\
g=\sec \theta\end{array}$ & 0669 & 0824 & 0791 \\
\hline$g=\cot \theta$ & 859 & 821 & 825 \\
\hline $\begin{array}{l}n=10 \\
g=\sec \theta\end{array}$ & 0928 & 1038 & 1016 \\
\hline $\begin{array}{l}n=10 \\
g=\cot \theta\end{array}$ & 411 & 329 & 340 \\
\hline
\end{tabular}
calculated for the values $n=0.2$ and $n=1$. The results are shown in table 2 .

TABLE 2-Comparative dose rates due to approximating a rectangular source by curcular sectors 
Assuming that the values in the final column are close to the true values, which would be obtained by integrating over the rectangle, the possible errors due to approximating a 1:5 rectangle by a circular disk (one sector) could be at most 25 percent. When the detector is close to the source $(n=0.2)$ the relative error is greatest for diffuse angular distribution, $g=\sec \theta$; when the detector is farther out, the relative error is greatest for the peaked distribution, $g=\cot \theta$. Most cases of practical interest will generally have much smaller errors because rectangular roofs are usually less eccentric and angular distributions lie between the two extremes. These errors, then, are inherent in the use of calculations for circular roof sources and barriers uniformly distributed between roof and detector.

\subsection{Angular Distributions}

Let us now discuss the basic angular distribution data from which the calculations were derived. The angular distributions at a height above an infinite plane isotropic source are given in figure Al.

In figure $A l, \theta$ is the polar angle between the direction of the radiation and the upward normal to the plane. The ordinate at $\cos \theta=1$ corresponds to radiation reaching the detector from below, that at $\cos \theta=0$ corresponds to the radiation intensity from the horizon, and that at $\cos \theta=-1$ corresponds to the radiation intensity from the zenith. The most significant feature of these curves is the gradual transition from a distribution for small heights which is sharply peaked at the horizon, to a distribution at great heights which is peaked in the direction of the source. For $\cos \theta>0.2$, the uppermost curve varies approximately as $\sec \theta$ and represents the extreme example of diffuseness referred to earlier.

The response to radiation from all directions by a detector at height $d$ above an infinite plane isotropic source is given by the integral over the appropriate curve in figure $A 1$. These curves are normalized so that the integrals yield reduction factors. The reduction factor as a function of height in air is shown in figure A2.

Since the attenuation properties of air and concrete are very similar [1], the parameter $d$ in figure A2 can be converted to the thickness $X$ of a concrete barrier by means of the relation:

$$
X(\mathrm{psf} \text { of concrete })=0.075 d(\text { feet of air })
$$

This relation is approximately valid for other light construction materials but does not apply to iron or lead. Furthermore, if $X$ is interpreted as the depth below, rather than the height above the source, then the new curve represents the reduction factor beneath a roof barrier of thickness $X$ which is covered by an infinite plane isotropic source. This curve is given as case 1 in figure Bl.

The next problem is to calculate the dose rate from source areas of finite extent. Consider the dose rate from a finite circular disk source. It is well known that the dose rate beneath the center of a circular clearing in an infinite plane isotropic source depends only on the slant distance $D$ to the nearest source, provided the source and detector are in an infinite homogeneous medium. If the detector is at a depth $X$, then the slant radius is given by

$$
D=X \sec \theta_{0}=X /(1-\omega)
$$

where $\omega$ is the solid angle fraction subtended at the detector by the clearing and $\theta_{0}$ is the angle between the slant radius and the normal to the plane. If $L(X)$ is the dose rate at a depth $X$ from an infinite plane isotropic source, then the dose rate beneath the center of the clearing is given by

$$
R(X)=L[X /(1-\omega)] \quad \text { (clearing) }
$$

and the dose rate beneath a circular disk source is

$$
R(X)=L[X]-L[X /(1-\omega)] \quad \text { (disk source) }
$$

Contour curves of the latter function are presented in figure $\mathrm{B} 4$, which was derived from figure 28.18 of [1]. The intersection of these contour curves with the $X_{0}=0$ psf axis give the reduction factor for a roof source subtending a solid angle fraction $\omega$ with no mass thickness between source and detector. Here again "no mass thickness" means $X_{0}=0.22 \mathrm{psf}$ ( $3 \mathrm{ft}$ of air), so that as $\omega$ approaches unity, the reduction factor approaches unity. The curve for $X_{0}=0$ is shown as case 1 in figure $\mathrm{B} 10$.

\section{Ground Sources}

\subsection{Schematization}

The calculation of radiation from sources on the ground surrounding a building is considerably more complicated than the calculation of radiation from roof sources. The basic difficulty is that the radiation from ground sources must penetrate a barrier which is perpendicular to the plane of the source material. Thus, there are two possible reference directions, namely, the direction normal to the source plane and the direction normal to the barrier. If the latter is chosen as the reference direction, and a detector location opposite the center of a rectangular wall is considered, the detector may be chosen as the origin of coordinates and the line through the detector and perpendicular to the barrier may be chosen as the polar axis. But, then, the angular distribution of radiation emerging from the wall is no longer azimuthally symmetric about a line perpendicular to the wall as it was in the case of radiation from the roof. For example, more radiation arrives from below the detector than from above it. Furthermore, walls are often about $10 \mathrm{ft}$ high per story, but over $50 \mathrm{ft}$ long. Thus, it is inaccurate to approximate these highly eccentric rectangles by circular disks. Since there is at present no information on responses from highly eccentric rectangles radiating with anisotropic azimuthal angular distributions, all angular distributions are referred to the (vertical) direction normal to the source plane. 


\subsection{Barrier and Geometry Factors}

If a source and detector are separated by a barrier and the detector is located some distance from the barrier it is sometimes convenient to separate the expression for the radiation intensity into two factors. The first factor, the barrier factor, depends only on the mass thickness, while the second factor, the geometry factor, depends primarily on the solid angle fraction subtended by the barrier and only weakly on the mass thickness. The geometry factor is a measure of the effect of the limited solid angle subtended by the radiating barrier. The concept of a geometry factor appears in other engineering disciplines such as heat exchange between rectangular radiation [5], particle detection [6], and illuminating engineering [7].

The separation can be derived mathematically as follows: Consider an angular distribution $g(X, \cos \theta)$ emerging from a circular slab of thickness $X$ and rewrite $g$ as

$$
\begin{aligned}
& g(X, \cos \theta)=\left\{\int_{0}^{1} g(X, \cos \theta) d(\cos \theta)\right\} \\
& \times\left\{g(X, \cos \theta) / \int_{0}^{1} g(X, \cos \theta) d(\cos \theta)\right\}
\end{aligned}
$$

or

$$
g(X, \cos \theta)=B(X) g^{\prime}(X, \cos \theta)
$$

where $B$ and $g^{\prime}$ are condensed notations for the first and second factors, respectively. From the definition of $g^{\prime}$ it can be seen

$$
\int_{0}^{1} g^{\prime}(X, \cos \theta) d(\cos \theta)=1
$$

The dose rate at a detector located some distance from a circular disk may be expressed as

$$
\begin{aligned}
& R=\int_{\cos \theta_{0}}^{1} g(X, \cos \theta) d(\cos \theta) \\
& =B(X) \int_{(1-\omega)}^{1} g^{\prime}(X, \cos \theta) d(\cos \theta)=B(X) G(X, \omega)
\end{aligned}
$$

where $\theta_{0}$ is the maximum polar angle subtended by the disk, as shown in figure 3 . The factors $B(X)$ and $G(X, \omega)$ are, respectively, the barrier and geometry factors.

In discussing radiation from ground sources advantage will be taken of this separation because the barrier factor has been calculated by Spencer but the geometry factor must be estimated. In discussing radiation from roof sources this separation is not necessary since Spencer has calculated the combined results of barrier and geometry directly.

\subsection{Thin-Walled Structures}

Consider first the case of an isolated story with no walls $\left(X_{w}=0 \mathrm{psf}\right)$ and infinitely thick floor and ceiling, as shown in figure 8 . If the detector

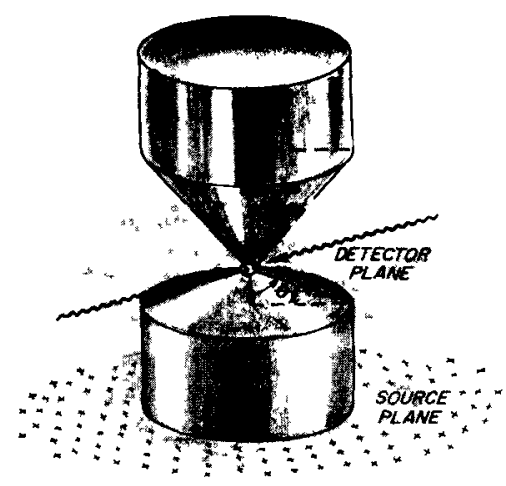

FIGURE 8. Idealized geometry for studying non-wall-scattered radiation.

plane is defined to be the horizontal plane passing through the detector, then the upward normal to the detector plane is the axis for the polar angle $\theta_{u}$ and the downward normal is the axis for the polar angle $\theta_{l}$.

The response of the detector can be calculated in terms of the curves of figure Al. First, the curve whose $d$-value corresponds to the height of the detector, measured in feet of air, is chosen. The $\theta_{u}$ and $\theta_{l}$ of figure 8 are related to the $\theta$ of figure Al by:

$$
\begin{gathered}
\cos \theta_{l}=\cos \theta, \quad 0 \leqslant \cos \theta \leqslant 1 \\
\cos \theta_{u}=|\cos \theta|, \quad-1 \leqslant \cos \theta \leqslant 0 .
\end{gathered}
$$

Directional responses are then obtained by integrating over the curve between appropriate limits. When $X_{w}=0$ psf the radiation reaches the detector without scattering in the wall. This is referred to as non-wall-scattered radiation. This awkward terminology arises because the radiation includes some air-scattered radiation and cannot therefore be referred to simply as "direct" radiation. The non-wall-scattered radiation reaching the detector from below the detector plane is given by

$G_{d}\left(\omega_{l}, H\right)=G_{d}\left(1-\cos \theta_{l}, d\right) \stackrel{\int_{0}^{\cos \theta_{l}} l(d, \cos \theta) d(\cos \theta)}{\int_{-1}^{1} l(d, \cos \theta) d(\cos \theta)}$

The notation on the right-hand side of eq (8) is that of [1]. The integrand $l(d, \cos \theta)$ is the angular distribution at a height of $d$ feet of air above a plane isotropic source. Note that the denominator is equal to unity for $d=3 \mathrm{ft}$.

$G_{d}\left(\omega_{l}, 3 \mathrm{ft}\right)^{6}$ is shown as the top curve in figure B5. It is a measure of radiation arriving from directions lying between the detector plane and the limits of the solid angle fraction $\omega_{l}$. It therefore decreases with increasing $\omega_{l}$. Curves for $G_{d}$ for other values of $d(\equiv H)$ are shown in figure $\mathrm{B} 6$.

In a similar manner, the non-wall-scattered radiation reaching the detector from above the detector

\footnotetext{
"In [2] the subscript " $"$ " stands for "lower" and the subscript " $d$ " stands for "direct"
} 
plane is given by

$$
\begin{aligned}
G_{a}{ }^{\prime}\left(\omega_{u}, d\right)=G_{a}{ }^{\prime}(1 & \left.-\cos \theta_{u}, d\right) \\
= & \frac{\int_{-\cos \theta_{u}}^{0} l(d, \cos \theta) d(\cos \theta)}{\int_{-1}^{1} l(d, \cos \theta) d(\cos \theta)} .
\end{aligned}
$$

This response can be expressed as a combination of functions which appear explicitly in [1]:

$$
G_{a}{ }^{\prime}\left(\omega_{u}, d\right)=\frac{S(d)}{L(d)}\left[1-S_{a}\left(d, \omega_{u}\right)\right]
$$

where

$$
\begin{aligned}
& L(d)=\int_{-1}^{+1} l(d, \cos \theta) d(\cos \theta) \\
& S(d)=\int_{-1}^{0} l(d, \cos \theta) d(\cos \theta)
\end{aligned}
$$

and

$$
\begin{aligned}
& S_{a}\left(d, \omega_{u}\right) \\
& \quad=\int_{-1}^{-\cos \theta_{u}} l(d, \cos \theta) d(\cos \theta) / \int_{-1}^{0} l(d, \cos \theta) d(\cos \theta)
\end{aligned}
$$

$S(d)$ shown in figure $A 3$ and $S_{a}(d, \omega)$ shown in figure $\mathrm{A} 4$ are taken from figures 28.15 and 28.3 , respectively, of [1]. $L(d)$ is shown in figure A2.

In order to account for radiation scattered from the ceiling a term was added to $G_{a}(\omega, d)$. This term was estimated using the following line of reasoning. Consider a detector as in figure 9 which receives radiation only from above the detector plane. Let the skyshine contribution be called $G\left(\omega_{u}\right)$. If the detector height is $3 \mathrm{ft}$, then

$$
G\left(\omega_{u}\right)=G_{a}^{\prime}(\omega, 3 \mathrm{ft}) .
$$

Remembering that geometry factors for ground sources increase with decreasing $\omega$, it can be seen that $G\left(\omega_{u}\right)$ increases as the size of the aperture $\left(1-\omega_{u}\right)$ increases. We would expect that the ceiling albedo would also vary as $G\left(\omega_{u}\right)$ because it too

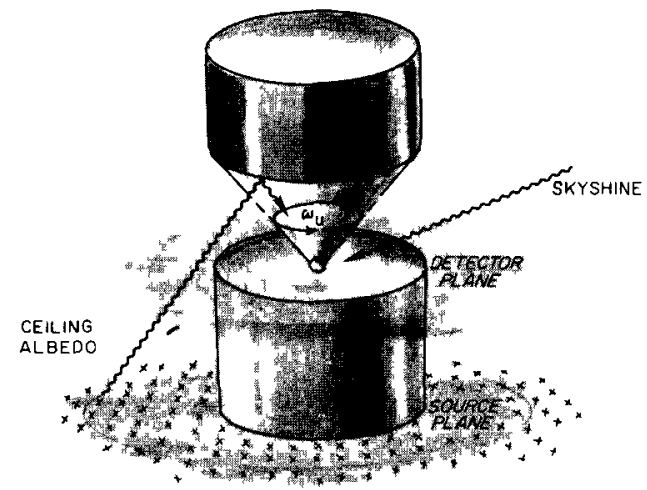

FIGURE 9 Idealized geometry lllustratıng typucal trajectories for gamma rays due to skyshıne and celling albedo must enter the structure through the apertures. However, unlike the skyshine, the ceiling albedo must approach zero as $\omega_{u}$ approaches zero since the scattering slab then subtends a vanishingly small solid angle fraction. This indicates the presence of another factor which was assumed to be

$$
\left[G(0)-G\left(\omega_{u}\right)\right]
$$

Therefore the combined skyshine and ceiling albedo are given by

$$
\begin{aligned}
G_{a}\left(\omega_{u}\right) & =G\left(\omega_{u}\right)+k G\left(\omega_{u}\right)\left[G(0)-G\left(\omega_{u}\right)\right] \\
& =G\left(\omega_{u}\right)\left\{1+k\left[G(0)-G\left(\omega_{u}\right)\right]\right\}
\end{aligned}
$$

To estimate the value of $k$, consider the limit of $G_{a}\left(\omega_{u}\right)$ as $\omega_{u} \rightarrow 1:$

$$
G_{a}\left(\omega_{u}\right) \rightarrow G\left(\omega_{u}\right)[1+k G(0)]
$$

since $G(1)<<G(0)$.

Now, by graphical or numerical integration of the uppermost curve in figure $A 1$ over negative values of $\cos \theta$ it is found that $G(0)=0.1$. Since there are no experiments or calculations to shed any light on what value of $k$ to choose, a value of $k=5$ was arbitrarily chosen so that the asymptotic ratio of ceiling albedo to skyshine as $\omega_{u} \rightarrow 1$ was taken to be $1 / 2$. The final expression for the combined response to skyshine and ceiling albedo,

$$
G_{a}\left(\omega_{u}\right)=G\left(\omega_{u}\right)\left\{1+5\left[0.1-G\left(\omega_{u}\right)\right]\right\},
$$

is given in figure B5.

The most serious shortcoming of this expression is that it specifies no dependence on the position of the sources. For example, most of the skyshine contribution comes from sources which are farther than $\sim 100 \mathrm{ft}$ from the structure, while most of the ceiling albedo probably comes from sources within $\sim 100 \mathrm{ft}$ of the structure. When a structure receives radiation from an infinite field it is probably sufficient to treat ceiling albedo as a correction factor. However, when the contamination width is less than $\sim 100 \mathrm{ft}$, it may be necessary to treat the ceiling albedo as a fourth type of source, in addition to the three types shown in figure 2 .

Since the variation of the skyshine angular distribution with height is very small, as shown in figure A4, this variation has been neglected. A chart for skyshine, analogous to the height variation of $G_{d}$ shown in figure B6, has therefore been omitted.

The basic curves of $l(d, \cos \theta)$ of [1] can also be used to treat a circular aperture in the roof or in a wall, when the detector lies on the axis of the aperture disk. The response from skyshine through a circular aperture in the roof is given by

$$
R=S(d) S_{a}(d, \omega) \quad \text { (Aperture in roof) }
$$

where $S(d)$ and $S_{a}(d, \omega)$ are given in figures $A 3$ and A4. In evaluating the response from a circular skylight no contribution from ceiling albedo is added. 
The response $R$ for a detector height of $d=0$ is plotted as case 3 in figure B10.

The response from radiation through a circular aperture in the wall is given by

$$
\begin{aligned}
R=\int_{\cos \Psi_{0}}^{1} d(\cos \Psi) \int_{0}^{2 \pi} p(\cos \Psi, \varphi) d \varphi / \\
\\
\int_{-1}^{1} d(\cos \Psi) \int_{0}^{2 \pi} p(\cos \Psi, \varphi) d \varphi
\end{aligned}
$$

where $p(\cos \Psi, \varphi)$ is the angular distribution of radiation arriving at the detector. The various angles are shown in figure 10 . In this figure, the detector is located at the origin and the direction of the radiation is indicated by the arrow. The angles $\Psi$ and $\varphi$ are the polar and azimuthal angles relative to the direction $O Z$, while $\theta$ is the polar angle relative to the direction $O Y$. The angle $\theta$ is related to $\Psi$ and $\varphi$ by

$$
\cos \theta=\sin \Psi \cos \varphi .
$$

Substituting the distribution $l$ for $p$ :

$$
R=\frac{\int_{\cos \Psi_{0}}^{1} d(\cos \Psi) \int_{0}^{2 \pi} l(3 \mathrm{ft}, \sin \Psi \cos \varphi) d \varphi}{\int_{-1}^{1} d(\cos \Psi) \int_{0}^{2 \pi} l(3 \mathrm{ft}, \sin \Psi \cos \varphi) d \varphi}
$$

$$
\text { (Aperture in wall). }
$$

The denominator guarantees a response of one-half for a detector located in the plane of the aperture at its center point $\left(\cos \Psi_{0}=0\right)$. The response $R$ for an aperture in a wall is given in case 2 of figure B10. Note that no ceiling albedo has been added to this contribution.

If response from an isolated aperture which is nearly square or circular in shape and which is directly opposite the detector is required, then this approach should be used. If apertures exist in a rectangular ribbon around the structure then the

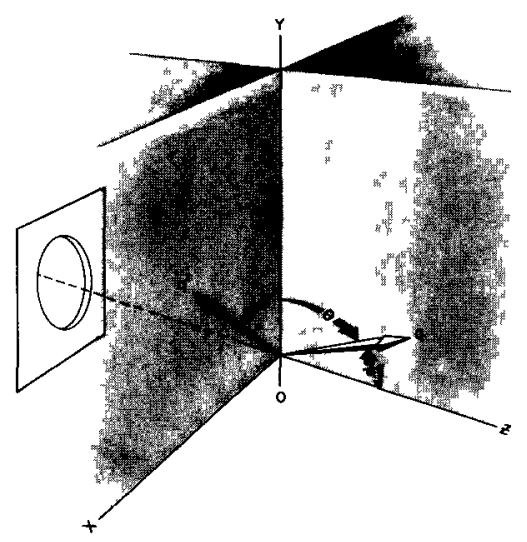

FIGURE 10 Coordınate systems relevant to an aperture in a vertical wall. $\Psi$ and $\varphi$ are the polar and azimuthal angles relative to the direc tion $O Z$ The angle $\theta$ is the polar angle relative to the direction $O Y^{\prime}$ curves in figure B5 for non-wall-scattered radiation should be used. If an aperture is at an eccentric position, that is, if a line from the detector, perpendicular to the wall, does not intersect the aperture, then the curves of figure B5 should be multiplied by the fraction of the azimuth subtended by the aperture.

\subsection{Thick-Walled Structures}

Consider now, the dose rate in a structure with very thick walls. The word "thick" as used here is relative to a mean free path for radiation. For fallout radiation a mean free path ${ }^{7}$ is about 40 psf. Therefore, a "thick" wall must be at least several times 40 psf in thickness. In the case of thick walls, assumptions have had to be made both about the angular distribution and the absolute magnitude of the radiation reaching the detector since neither has been calculated precisely,

Consider first the polar angular distribution, relative to the vertical direction, of radiation from thick walls of a structure. It has been assumed that the angular distribution is the same as that of the airscattered radiation in a structure with walls of zero thickness. This assumption might be justified on the following grounds. Much of the air-scattered radiation arises from the sources of the order of a mean free path away. Since the intervening air can be imagined as a barrier similar to the actual wall barrier, the angular distributions emerging from the two barriers might be expected to resemble each other. It was therefore assumed that the response to skyshine,

$$
G(\omega)=\int_{\cos \theta_{0}=-(1-\omega)}^{0} l(3 \mathrm{ft}, \cos \theta) d(\cos \theta),
$$

could be used to represent wall-scattered radiation from both above and below the detector plane. It was assumed furthermore that if the solid angle subtended by the ceiling was equal to the solid angle subtended by the floor then the response from below the detector plane would be equal to that from above the detector plane. This is equivalent to assuming that the multiple scattering in a wall will tend to wash out the asymmetry in intensities from above and below, which exists in the radiation incident on the wall. When $\omega=0$, the maximum response $G(0)$ either from below or from above the detector should be obtained. Since this maximum response should be one-half, $G(0)$ must be multiplied by a constant $k$ such that

$$
\begin{aligned}
& k G(0)=1 / 2 . \\
& \text { Since } G(0)=\int_{-1}^{0} l(d, \cos \theta) d(\cos \theta)=0.1, k=5 . \quad \text { The }
\end{aligned}
$$
response to wall-scattered radiation $G_{8}(\omega)$, is therefore given by

$$
G_{s}(\omega)=5 \int_{-(1-\omega)}^{0} l(3 \mathrm{ft}, \cos \theta) d(\cos \theta) .
$$

${ }^{7}$ Strictly speakung, the mean free path $1 \mathrm{~s}$ not defined for a spectrum, such as that from fallout However, the mean free path may be considered roughly as that distance in which the intensity of the direct radiation is reduced by a factor of $e$ 


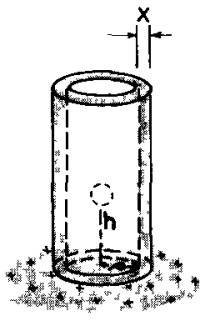

(a)

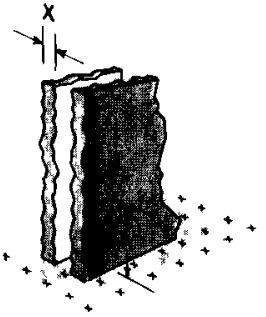

(b)
FIGURE 11(a). Detector located in a cylinder of infinite height.

(b). Detector located between two parallel walls of infinite length and height.

The curve for $G_{s}(\omega)$ is shown as the scattered case of figure B5. Like $G_{d}$, it does not include any contribution from radiation scattered from the ceiling or floor of the structure.

Assuming that the geometry factor is known, the barrier factor $B(X, h, \rho)$ for a right circular cylinder of infinite height, $\left(\omega_{u}=0\right)$ must still be determined. This barrier factor is a function of the height $h$ of the detector, and the radius $\rho$ and the wall thickness $X$ of the cylinder (figure 1la). The only barrier factors that have been calculated, however, give the dose rate between two infinitely high and wide plane walls due to a semi-infinite source on each side (figure 1lb). The necessity of using the latter barrier factor in a scheme involving cylindrical geometry constitutes a serious logical defect in the approach used in the engineering method. As pointed out earlier, however, if a geometry based on the orientation of the detector with respect to each wall had been used, equally serious defects would be present.

The barrier factor for a plane wall of infinite height and width is illustrated in figure 28.7 of [1]. The same curves multiplied by 2 and plotted in contours are shown in figure B2. The top curve of figure 28.7 corresponding to a detector height of $3 \mathrm{ft}$ is also shown as case 2 of figure B1.

Spencer's original curve [1] comes into a value greater than 0.5 at $X=0$. The excess over 0.5 represents backscatter from the wall behind the detector. In order to be consistent with a normalization of unity for a detector between two walls of zero thickness, the curve was lowered near $X=0$ so that it came into 0.5. The entire curve was then multiplied by 2 to obtain the curve in figure B1.

Some correction must now be applied to this barrier factor to account for the shape of the structure. Although the geometry factors for ground sources are based on circular structures, they are applied in most cases to rectangular structures. The correction for the shape of the structure is therefore derived in terms of rectangular structures, first. The correction for a circular structure is then discussed as a limiting case.

Consider first the ratio of dose rates inside of two infinitely high thick-walled buildings - one with four walls of equal length (i.e., a square tower) and the other with two infinitely long walls separated by a distance equal to the side of the square. In order to

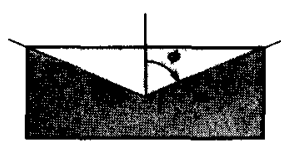

(a)

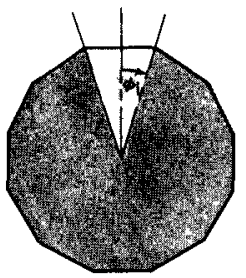

(b)
FIGURE 12(a). Azimuthal angle $\varphi$ for a rectangle.

(b). Azimuthal angle for a many-sided polygon.

calculate this ratio, an assumption must be made concerning the distribution of radiation in the azimuthal direction, about the vertical axis. Evidence from calculated angular distributions at great depths from a point isotropic source indicates that the azimuthal distribution is not isotropic but more peaked in a direction normal to the wall. The azimuthal angular distribution $p(\varphi)$ emerging from each wall was assumed to be of the form

$$
p(\varphi) d \varphi=\frac{\cos \varphi d \varphi}{2}
$$

where $\varphi$ is measured relative to that azimuthal plane which is perpendicular to the wall. Then, the response in an infinitely high, thick-walled rectangular structure (fig. 12a) whose length-to-width ratio is $L / W$ is obtained by summing over four walls:

$$
\begin{gathered}
E=\sum_{i=1}^{4} \int_{0}^{\varphi_{i}} p(\varphi) d \varphi=\sum_{i=1}^{4} \frac{\sin \varphi_{i}}{2} \\
=\frac{2}{2}\left[\frac{L}{\sqrt{L^{2}+W^{2}}}+\frac{W}{\sqrt{L^{2}+W^{2}}}\right] \\
E=(L+W) / \sqrt{L^{2}+W^{2}}=(1+e) / \sqrt{1+e^{2}}
\end{gathered}
$$

with $e=W / L$. For a square building $e=1$ and $E=\sqrt{2}$, while for an infinitely long, narrow building $e \rightarrow 0$ and $E \rightarrow 1$. The ratio of dose rates in the two structures is therefore $\sqrt{2}$. The expression $E$, known as the eccentricity factor, is shown in figure B8.

The response in a circular structure is obtained from the limit of the response in a many-sided polygon shown in figure $12 \mathrm{~b}$ :

$$
R=\lim _{N \rightarrow \infty} \sum_{i=1}^{N} \frac{\sin \varphi_{l}}{2}=\lim _{N \rightarrow \infty} \frac{\pi}{2} \frac{\sin \frac{\pi}{N}}{\frac{\pi}{N}}=\frac{\pi}{2} .
$$

If the separation of the two walls in figure $11 \mathrm{~b}$ is $2 \rho$, then the dose rate in the configuration of figure lla would be greater than that in configuration $11 \mathrm{~b}$ by a factor of $\pi / 2$.

It has been assumed that this eccentricity factor can also be applied when the walls are of finite height. There have not yet been any direct experimental tests of the assumption. It is confirmed only indirectly by the general agreement of experiments with the calculations. 


\subsection{Walls of Intermediate Thickness}

The vast majority of structures has walls that are neither very thick nor very thin. In view of the lack of data it was decided merely to take a weighted ratio of the thick-wall geometry factor (eq (14)) and the thin-wall geometry factors (eqs (8) and (11)), with the weighting factor $S_{w}(X)$ assumed to be a function only of $X$ :

$$
G(\omega, X)=S_{w}(X) G_{\text {Thick }}+\left[1-S_{w}(X)\right] G_{\text {Thin }}
$$

where

and

$$
G_{\text {Thick }}=\left[G_{s}\left(\omega_{l}\right)+G_{s}\left(\omega_{u}\right)\right] E
$$

$$
G_{\text {Thin }}=G_{d}\left(\omega_{l}\right)+G_{a}\left(\omega_{u}\right) .
$$

Strictly speaking, the weighting factor represents the fraction of radiation reaching the detector which has been scattered at least once in the walls. It, therefore, probably varies somewhat with $\omega$, but this effect has been ignored. The values of $S_{w}(X)$ were determined from data on the perpendicular incidence of Co 60 radiation. If $B_{p}(X)$ is the buildup factor for perpendicular incidence,

$$
S_{w}(X)=\frac{B_{P}(X)-1}{B_{P}(X)} .
$$

A more appropriate choice might have been the ratio of scattered-to-total radiation for a point isotropic fission product source. This can be determined from figure 28.6 of [1]. It differs by less than 10 percent from the curve shown in figure B7. Furthermore, the results are not very sensitive to the curve assumed for $S_{w}(X)$ because the factors $G_{\text {Thick }}$ and $G_{\text {Thin }}$ often differ by less than 50 percent over a large range of $\omega$. This lack of sensitivity suggests the possibility of using some average $G(\omega)$ for all wall thicknesses instead of distinguishing between $G_{\text {Thick }}$ and $G_{\text {Thin }}$. Such a simplification, however, must await a more accurate determination of the geometry factors as a function of solid angle and wall thickness.

The expression for the geometry factor for thin walls given in eq (18) should really have an eccentricity factor, analogous to that in eq (17). This factor would be unity for a circular structure and approximately unity for a square structure. The factor would decrease (as does the eccentricity factor for scattered radiation) for more elongated buildings whose floors subtend the same solid angle. It was not calculated because it was thought that it would only be important in areas with low protection factors since the direct geometry factor is important only for thin walls. There are some situations where this may not be true, however. For example, in buildings with very thick walls and small apertures, the direct radiation may make the dominant contribution in an otherwise well-protected location. The eccentricity factor for direct radiation should probably be included in those cases. It could be obtained as a function of $H, W / H$, and $L / H$ from the work of Hubbell [8],

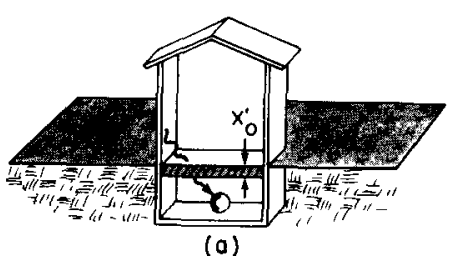

(a)

ACTUAL

Figure 13(a). Actual configuration for penetration of skyshine through a basement ceiling.

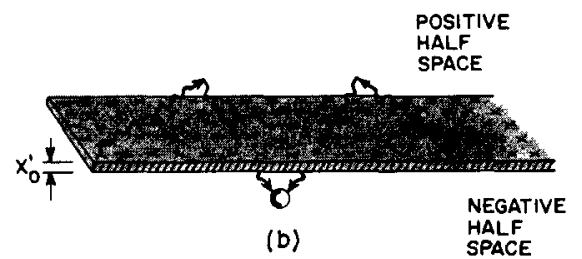

SCHEMATIZED

FIGURE 13(b). Schematized configuration for penetration of skyshine through a basement ceiling.

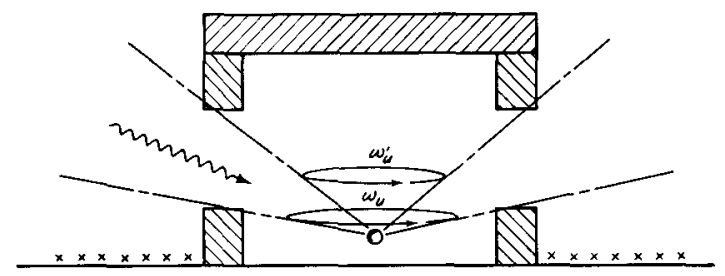

FIGURE 14. Schematized geometry for skyshine through apertures, showing the two relevant solid angle fractions.

$H$ being the detector height, $W$ the width of the building, and $L$ the length of the building.

\section{Skyshine}

As indicated in figure 2, skyshine arises from radiation which originates from sources on the ground and roof and arrives from above the detector after undergoing one or more scatterings in the volume of air surrounding the structure.

Skyshine may make an important contribution whenever a detector is well shielded from direct radiation. Two cases of importance are a detector located in a basement covered by a relatively heavy slab, but with an otherwise light superstructure above it (fig. 13a), and a detector located below sill level in a structure with heavy walls and floors (fig. 14).

Consider first the penetration of skyshine through a slab over a basement. Spencer has calculated the intensity of radiation behind a barrier located in the negative half-space due to radiation originally emitted into the positive half-space. This configuration is shown in figure $13 \mathrm{~b}$. The corresponding barrier curve is given as case 3 in figure B1.

The situation in figure $13 \mathrm{~b}$ differs from that in $13 \mathrm{a}$ in that $13 \mathrm{~b}$ contains an infinite plane source while 13a contains a clearing surrounded by walls. 
Some unpublished calculations by Spencer indicate that the penetration of radiation to a detector beneath a clearing without walls is similar to the situation in $13 \mathrm{~b}$ provided the radius of the clearing is small compared to the mean-free-path in the backscattering medium ( $\sim 500 \mathrm{ft}$ in air). Most buildings satisfy this criterion. However, the presence of the walls may distort the angular distribution of radiation incident on the clearing from overhead. In particular, the strong component at grazing incidence which is present in configuration $13 \mathbf{b}$, and which affects the shape of the barrier curve, may be considerably suppressed in configuration 13a. For lack of any more precise data, however, the two configurations have been assumed to be equivalent.

Consider next the skyshine radiation through apertures in a building with thick walls (see fig. 14). This is merely a special case of non-wallscattered radiation received from above the detector. However, the limits of the aperture define two solid angles which both lie above the detector. Since the geometry curves of figure B5 give the response to radiation arriving from all directions between the horizontal and an arbitrary limit, the responses must be differenced when both limits are above (or below) the horizon. Therefore,

$$
R=G_{a}\left(\omega_{u}{ }^{\prime}\right)-G_{a}\left(\omega_{u}\right),
$$

where $\omega_{u}$ and $\omega_{u}^{\prime}$ are the solid angle fractions shown in figure 14 .

\section{Limited Source Areas}

The barrier and geometry factors developed in the preceding sections enable one to calculate the reduction factor in an isolated structure located in an infinite field of fallout radiation sources. In many cases of practical interest, however, buildings are surrounded by a series of finite rectangular source areas. It is therefore necessary to calculate reduction factors for such sources.

A solution for a rectangular source area can be obtained by applying a correction to the infinite plane result or by integrating over results for point sources arranged in a rectangular array. The former approach has been taken primarily because barrier and geometry factors for radiation incident on a wall from point sources on the ground have not yet been calculated. It is possible, however, that in solutions for small areas (i.e., when the width of the strip is equal to or less than the height of the detector above the strip) the small areas should eventually be treated as a collection of point sources.

The basic assumption made in treating finite rectangular sources is that non-wall-scattered and wall-scattered radiation must be treated differently. Non-wall-scattered radiation in a structure such as shown in figure 15, upper left, will depend on the solid angle $\omega$ subtended by the source area, at the detector position, since it is composed mainly of radiation which travels directly from source to detector. In the case of wall-scattered radiation, however, the wall acts as a secondary source. The radiation impinging on the wall depends on the solid angle fraction $\omega_{2}$ (figure 15, lower right), subtended at the center of the wall by the source area. The radiation scattered in the wall and reaching detector $D$ depends on the solid angle fraction $\omega_{1}$ subtended at $D$ by the wall. Thus, the wall-scattered radiation depends on two solıd angles.

In calculating the barrier factor for non-wallscattered radiation from a rectangular source, case 2 of figure $B 1$ is used just as for the infinite plane source. However, the geometry factor is obtained from figure B6 by differencing between the response for the outer dimensions of the source area and the response for the inner dimensions:

$$
\Delta G_{d}=G_{d}\left(\omega_{i}, H\right)-G_{d}\left(\omega_{0}, H\right),
$$

where $\omega_{l}$ is the solid angle fraction subtended at the detector by the inner dimensions of the annulus and $\omega_{0}$ is the solid angle fraction subtended by the outer dimensions. Notice that in calculating this geometry factor the source is considered as an annulus surrounding the building. As the strip approaches an infinite field, $\omega_{0} \rightarrow 1, G_{d}\left(\omega_{0}, H\right) \rightarrow 0$, and the difference reduces to the usual single term for an infinite source. Since the geometry factor takes into account the variations in source geometry, the barrier factor is assumed for convenience to be independent of source geometry.

In calculating the contribution from wall-scattered radiation, the $G_{s}$ curve of figure $B 5$ is used for the geometry factor since the geometry factor for wallscattered radiation is assumed to be independent of the source geometry. This assumption was made because of the lack of any data in this area. The barrier factor for wall-scattered radiation from finite sources shown in figure B9 was based on unpublished calculations of Spencer, in which he

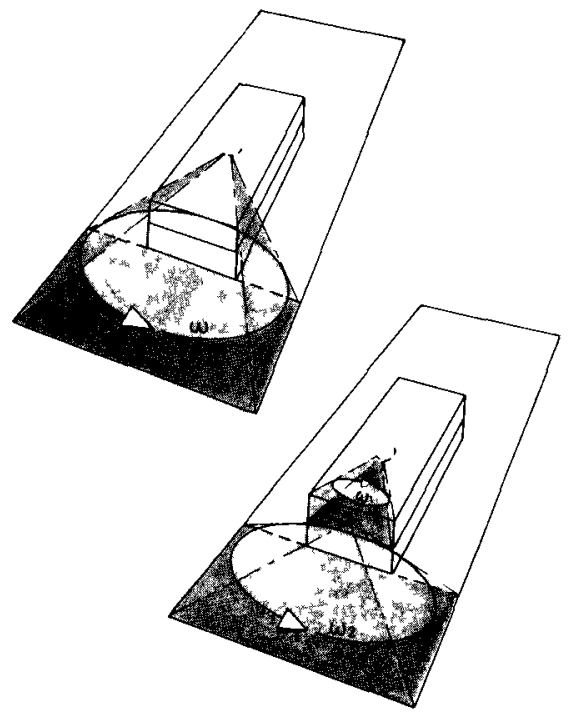

FiguRE 15. Solld angles related to radiation recelved from a fintte source of contamination. Direct radiation (upper left) and wall scattered radiation (lower $n g h t$ ) 
calculated the dose rate behind a wall due to direct radiation from semicircular sources. These semicircles were concentric about a point at the base of the wall directly below the center of the wall as shown in the right-hand diagram of figure 16 . The results are a function of the wall thickness and the solid angle fraction $\omega_{s} / 2$ subtended by the source. When the radius $\rho$ of the semicircle is equal to or less than the detector height, the barrier factor is extremely sensitive to the value of $\omega_{s}$.

It was necessary to define a relationship between the solid angles of the semicircles for which results were calculated and the solid angles of the rectangular sources encountered in practice (see figure 16). This relationship was set up to preserve the solid angle subtended at a detector point on the wall:

$$
\omega_{s}=(1-\cos \theta)=\frac{2}{\pi} \tan ^{-1} \frac{e}{n \sqrt{n^{2}+e^{2}+1}}
$$

with $\theta, n, e$ defined in figure 16 .

The calculation of wall-scattered radiation from finite sources must be calculated for each wall. When the sources lie on more than one side of the building as in figure 15 there is some ambiguity in defining the strip length $L$ indicated in figure 16 . The only guiding rule that can be given is to divide the rectangular annulus arbitrarily so that each partial area contributes to one side only. It is true that, in reality, sources lying on the corner areas may contribute through both walls. However, this effect is already taken into account by the eccentricity factor. In fact, recognizing that some sources contribute through more than one wall is an alternate way of justifying the introduction of an eccentricity factor. ${ }^{8}$

\section{Point Source}

The penetration of radiation from a localized source can be approximated by penetration of radiation from a point source if it is far enough away so that it subtends a small solid angle at the

${ }^{8}$ From this viewpoint, the dose rate at the detector is regarded as a sum of contributions from each source. The shape of the structure influences the relative contribution of each source. The viewpoint taken in sec. 4.4 is that the dose rate is a sum of phofrom each direction.

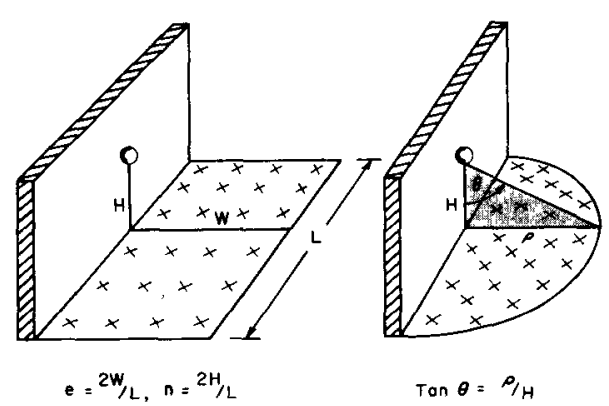

FIGURE 16. Rectangular and semicircular sources adjoining a vertical wall.

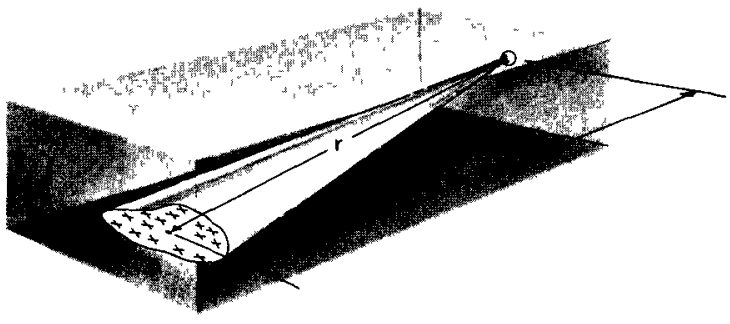

FIGURE 17. Localized source area A at a distance $\mathrm{r}$ from a detector with intervening mass thickness $\mathrm{X}$.

Source and detector are immersed in a homogeneous medium.

detector. Indeed, as was discussed in section 6 , the results for point sources may eventually lead to evaluation of radiation from small finite source areas. The attenuation of radiation from a localized source through an absorber thickness $X$ is given as the curve $P(X)$ in figure $28.5 \mathrm{~b}$ of [1]. The configuration to which the curve applies is shown in figure 17 of this report. The curve is related to the reduction factor $R_{f}$ from a plane source by the expression

$$
R_{f}=\frac{P(X) A}{4 \pi r^{2}} \quad \text { Reference }[1]
$$

where $A$ is the area of the localized source and $r$ is the distance from source to detector. If one integrated over a large number of small patches covering a plane, the integrated dose at a detector $3 \mathrm{ft}$ in air above the plane would be unity. Thus, the above expression yields a true reduction factor. The curve has been replotted in figure B1l and normalized to unity. If the curve from figure $B 11$, denoted by $P_{s}\left(X_{w}\right)$ in [2], is used for a localized plane patch of sources and a reduction factor is desired, then

$$
R_{f}=\frac{0.36 P_{s}\left(X_{w}\right) A}{4 \pi r^{2}} \quad \text { Reference }[2]
$$

\section{Interior Partitions}

Calculational procedures have now been developed for building shells, with no internal structure except floors. Although the effect of interior partitions may be regarded from the standpoint of calculations as a correction factor, in practice it may well introduce factors of two or more in protection.

Consider first the penetration of radiation from roof sources through interior walls (see inset diagram of fig. B12). In the interim edition of [2] it was recommended that the barrier curves illustrated in figure $\mathrm{B} 2$ be used to calculate the penetration through interior walls. The procedure was to convert the roof thickness in psf to feet of air and to use this value for the height above the plane when reading values from the chart. The justification for this procedure was that the angular and energy distribution of radiation emerging from the underside of the ceiling was approximately equal to that at a corresponding height in air above a plane 
isotropic source and should therefore penetrate a vertical wall with the same efficiency. The barrier curve $B_{\imath}$ for an interior wall of thickness $X_{\imath}$ was normalized by expressing it as a ratio

$$
B_{\imath}=\frac{B\left(X_{\imath}, H\right)}{B(0, H)}
$$

$B(X, H)$ being obtained from figure $\mathrm{B} 2$. It was found, however, that the curves for $B_{2}$ were not very sensitive to the value of the roof thickness $X_{0}$, particularly for values of $X_{0}$ greater than 10 psf. Accordingly, the curve for $X_{0}=50 \mathrm{psf}$ was chosen as a representative value and is reproduced in figure $\mathrm{B} 12$.

Consider next the penetration of radiation from ground sources through interior partitions. When the calculational procedures were developed there existed virtually no calculations or experiments to serve as a guide in the treatment of interior partitions. The recommended procedure was to multiply by a barrier factor equal to that for an exterior wall of the same mass thickness (case 2, figure B1). Assuming that this procedure is valid, it is an unambiguous recommendation for structures whose interior partitions resemble those in figure 18a. However, for the structure of figure $18 \mathrm{~b}$ and the fairly common one shown in figure $18 \mathrm{c}$, the reader is forced to use his own judgment. These problems can be handled by dividing the building into several azimuthal sectors centered on the detector. Although the number and thickness of partitions lying between the detector and the source can then be specified, the applicable barrier and geometry factors remain ambiguous. The present recommendations for treating the structure of figure $18 \mathrm{~b}$ are to consider the contribution wall by wall, including the interior barrier factor only for the wall on the right. The structure of figure $18 \mathrm{c}$ may be treated by first folding the transverse walls into the main corridor wall and then assuming interior partitions of effective mass thickness $\left(X_{i}+k X_{2}^{\prime}\right)$ surrounding the detector. As a first approximation $k$ may be set equal to unity, but we do not really know how effective these transverse partitions are in shielding a detector in the central corridor. Preliminary experiments on model structures by Technical Operations, Inc., [12] indicate that this approach is reasonable, but that $k$ should be set equal to $1 / 2$.

\section{Comparison with Experiment}

In developing the calculations discussed in this report, an attempt was made to consider all experimental data available. Although experiments are not without ambiguities, they have pointed out some of the weak points in the present calculations. Since a careful analysis of all the experimental data has not yet been made, only those experiments which seem to indicate the main areas where revisions in the calculations are necessary will be quoted. Unfortunately, the experiments do not always indicate in precisely what manner the calculations ought to be changed.

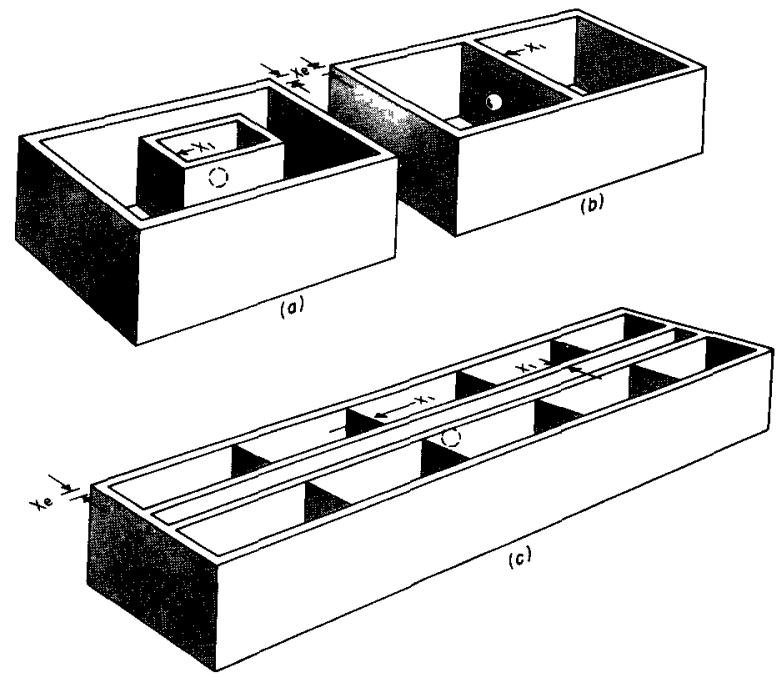

FIGURE 18 Three posstble configurations for interior partitions.

Experiments $[9,10]$ on a square concrete blockhouse at the Army Chemical Center in Edgewood, Md., provided, for a long time, the only experimental data with which calculations could be compared. As shown in tables 3 and 4, agreement between experiment and calculations is generally about 20 percent for Co 60 radiation and 40 percent for $\mathrm{Cs} 137$ radiation. Since the geometry factors for the blockhouse were close to unity these experiments did not provide a sensitive test of the calculations.

More recent experiments by Technical Operations, Inc., [11] on a steel model of a six-story building provide a more sensitive test of geometry factor. In analyzing their experiments, however, two assumptions must be made. It must be assumed that experimental results on a model whose

TABLE 3a-Reduction factors for roof sources, Co 60 source [9]

\begin{tabular}{|c|c|c|c|c|c|c|}
\hline Detector helght & \multicolumn{2}{|c|}{$H=0 \mathrm{ft}$} & \multicolumn{2}{|c|}{$H=3 \mathrm{ft}$} & \multicolumn{2}{|c|}{$H=6 \mathrm{ft}$} \\
\hline $\begin{array}{c}\text { Roof thuckness } \\
X_{0}\end{array}$ & Exp & Calc & Exp & Calc & Exp & Calc \\
\hline $\begin{array}{cc}p s f & \\
3303 \\
171 \\
317 \\
421 \\
501\end{array}$ & $\begin{array}{r}0069 \\
0058 \\
043 \\
032 \\
027\end{array}$ & $\begin{array}{r}0050 \\
044 \\
035 \\
030 \\
025\end{array}$ & $\begin{array}{r}0113 \\
090 \\
061 \\
044 \\
037\end{array}$ & $\begin{array}{r}0095 \\
080 \\
060 \\
050 \\
042\end{array}$ & $\begin{array}{r}0241 \\
041 \\
092 \\
064 \\
053\end{array}$ & $\begin{array}{c}022 \\
16 \\
105 \\
080 \\
\text { c65 }\end{array}$ \\
\hline
\end{tabular}

TABLE 3b. - Reduction factors for roof sources, Cs 137 source [9]

\begin{tabular}{c|r|r|r|r|r|r}
\hline \hline Detector height & \multicolumn{2}{|c|}{$H=0 \mathrm{ft}$} & \multicolumn{2}{c|}{$H=3 \mathrm{ft}$} & \multicolumn{2}{c}{$H=6 \mathrm{ft}$} \\
\hline $\begin{array}{c}\text { Roof thrckness } \\
X_{0}\end{array}$ & Exp & Calc & Exp & Calc & Exp & Calc \\
\hline & & & & & & \\
\hline psf & & & & & & \\
303 & 0071 & 0050 & 0114 & 0095 & 023 & 021 \\
171 & $\mathbf{0 5 2}$ & 043 & 079 & 080 & 124 & 16 \\
317 & 032 & 034 & 046 & 056 & 065 & 090 \\
421 & 022 & 026 & 030 & 045 & $\mathbf{0 3 8}$ & $\mathbf{0 6 5}$ \\
501 & $\mathbf{0 2 0}$ & 023 & 027 & 035 & $\mathbf{0 3 6}$ & $\mathbf{0 5 0}$ \\
\hline
\end{tabular}


TABLE 4a - Reduction factors for ground sources, Co 60 source [10]

\begin{tabular}{|c|c|c|c|c|c|c|}
\hline \multirow{2}{*}{$\begin{array}{l}\text { Detector height } \\
\underset{X}{\text { Wall thickness }}\end{array}$} & \multicolumn{2}{|c|}{$H=0 \mathrm{ft}$} & \multicolumn{2}{|c|}{$H=3 \mathrm{ft}$} & \multicolumn{2}{|c|}{$H=6 \mathrm{ft}$} \\
\hline & $\operatorname{Exp}$ & Calc & $\operatorname{Exp}$ & Calc & $\operatorname{Exp}$ & Calc \\
\hline $\begin{array}{r}48 \\
94 \\
139\end{array}$ & $\begin{array}{l}022 \\
071 \\
022\end{array}$ & $\begin{array}{c}0128(0226)^{*} \\
051\left(\begin{array}{ll}071 \\
0\end{array}\right)^{*} \\
019(024)^{*}\end{array}$ & $\begin{array}{c}028 \\
10 \\
033\end{array}$ & $\begin{array}{r}0302 \\
103 \\
036\end{array}$ & $\begin{aligned} 026 \\
096 \\
029\end{aligned}$ & $\begin{array}{r}0260 \\
080 \\
035\end{array}$ \\
\hline
\end{tabular}

TABLE 4b - Reduction factors for ground sources, Cs 137 source [10]

\begin{tabular}{|c|c|c|c|c|c|c|}
\hline \multirow{2}{*}{$\begin{array}{l}\text { Detector height } \\
\text { Wall thickness } \\
X\end{array}$} & \multicolumn{2}{|c|}{$H=0 \mathrm{ft}$} & \multicolumn{2}{|c|}{$H=3 \mathrm{ft}$} & \multicolumn{2}{|c|}{$H=6 \mathrm{ft}$} \\
\hline & Exp & Calc & Exp & Calc & $\operatorname{Exp}$ & Calc \\
\hline $\begin{array}{rr}p s f & \\
& 48 \\
94 \\
139\end{array}$ & $\begin{array}{l}013 \\
035 \\
0085\end{array}$ & {$\left[\begin{array}{ccc}0097(0169)^{*} \\
029\left(0^{041}\right)^{*} \\
0067(0086)^{*}\end{array}\right.$} & $\begin{array}{l}020 \\
050 \\
011\end{array}$ & $\begin{array}{l}0227 \\
059 \\
0128\end{array}$ & $\begin{array}{l}018 \\
\quad 046 \\
0097\end{array}$ & $\begin{array}{c}0186 \\
046 \\
0104\end{array}$ \\
\hline
\end{tabular}

Numbers in parentheses include direct radiation The
included in the experimental results for $H=0$ is uncertain

dimensions are scaled down by a ratio of 12 to 1 are applicable to a full size structure. This is expected to be valid provided that the room dimensions in the model are at least ten times the wall thickness in the model. This condition was satisfied by the models used in the Technical Operations, Inc., experiments. It must also be assumed that steel and concrete have the same barrier factors for equal weights per unit area of barrier thickness. Spencer has shown that the barrier factors are approximately equal for perpendicular incidence ${ }^{9}$ but this equality has not been demonstrated for other angles of incidence.

The main purpose of the experiment performed by Technical Operations, Inc., on the multistory steel model, was to test calculations for rectangular source annuli surrounding a structure. The measurements, however, included the case of an infinite field. Table 5 gives the reduction factors at three heights on six stories of two different models of structures surrounded by an infinite field of contamination. The upper tabulation applies to a structure with floors of two inches of iron $(80 \mathrm{psf})$ and walls of $1 / 2$ in. of iron ( $20 \mathrm{psf})$. The lower tabulation applies to a structure with floors and walls of $80 \mathrm{psf}$. The experimental values are taken from [11] but the calculated values are those of the author. The experimental dose rates increase more rapidly with height above the floor than predicted by the calculations. This may indicate that the scattered radiation emerging from the walls is not symmetrical with respect to the horizontal, but is more peaked in the upward direction. This in turn suggests that the geometry curve for wallscattered radiation from the lower hemisphere should be different from that for the upper hemisphere.

${ }^{9}$ See figure 221 of $[1]$ Since the curves of fig 221 are plotted aganst mass thick ness, the abscissa for steel should be multuplied by $1 / 093$ to obtain a comparison on the basis of wejght per unit area
TABLE 5 -Reduction factors in T/O multistory steel model [11] Thickness of walls $=20 \mathrm{psf}$

Thuckness of floors $=80 \mathrm{psf}$

\begin{tabular}{|c|c|c|c|c|c|c|}
\hline \multirow{2}{*}{$\begin{array}{c}\begin{array}{c}\text { Detector } \\
\text { height } \\
\text { above floor }\end{array} \\
\text { Story }\end{array}$} & \multicolumn{2}{|c|}{$H=3 \mathrm{ft}$} & \multicolumn{2}{|c|}{$H=6 \mathrm{ft}$} & \multicolumn{2}{|c|}{$H=9 \mathrm{ft}$} \\
\hline & Exp & Calc & Exp & Calc & Exp & Calc \\
\hline $\begin{array}{l}1 \\
2 \\
3 \\
4 \\
5 \\
6\end{array}$ & $\begin{array}{c}036 \\
19 \\
12 \\
096 \\
068 \\
054\end{array}$ & $\begin{array}{c}038 \\
26 \\
194 \\
154 \\
124 \\
102\end{array}$ & $\begin{array}{r}036 \\
24 \\
19 \\
15 \\
12 \\
11\end{array}$ & $\begin{array}{c}038 \\
28 \\
22 \\
176 \\
146 \\
119\end{array}$ & $\begin{array}{r}035 \\
27 \\
22 \\
18 \\
16 \\
14\end{array}$ & $\begin{array}{l}035 \\
28 \\
22 \\
179 \\
145 \\
117\end{array}$ \\
\hline
\end{tabular}

Theckness of wals and floors $=80 \mathrm{psf}$

\begin{tabular}{|c|c|c|c|c|c|c|}
\hline $\begin{array}{l}\text { Detector } \\
\text { helght }\end{array}$ & \multicolumn{2}{|c|}{$H=25 \mathrm{ft}$} & \multicolumn{2}{|c|}{$H=5 \mathrm{ft}$} & \multicolumn{2}{|c|}{$H=75 \mathrm{ft}$} \\
\hline Story & Exp & Calc & Exp & Calc & Exp & Calc \\
\hline $\begin{array}{l}1 \\
2 \\
3 \\
4 \\
5 \\
6\end{array}$ & $\begin{array}{r}0098 \\
051 \\
040 \\
043 \\
025 \\
021\end{array}$ & $\begin{array}{r}0072 \\
048 \\
037 \\
030 \\
024 \\
020\end{array}$ & $\begin{array}{r}0107 \\
062 \\
050 \\
036 \\
035 \\
032\end{array}$ & $\begin{array}{r}0075 \\
054 \\
042 \\
034 \\
028 \\
023\end{array}$ & $\begin{array}{r}0098 \\
067 \\
055 \\
050 \\
038 \\
037\end{array}$ & $\begin{array}{r}0067 \\
049 \\
039 \\
032 \\
026 \\
022\end{array}$ \\
\hline
\end{tabular}

Reduction factors for finite rectangular annuli surrounding the Technical Operations model are shown in figures 19 and 20 . Results are plotted against the ratio of the width of the annulus to the height of the detector above the source. Comparison of the experimental and calculated results shows good agreement for both structures, except for the first story. It should be borne in mind, however, that for the first story, values of $W_{c} / H$ of less than 5 are not of much practical interest. The curve in figure 19 indicates the experimentally observed increase in dose rate when the floors of the model are thin. The increase is due to penetration of radiation from stories below the one at which

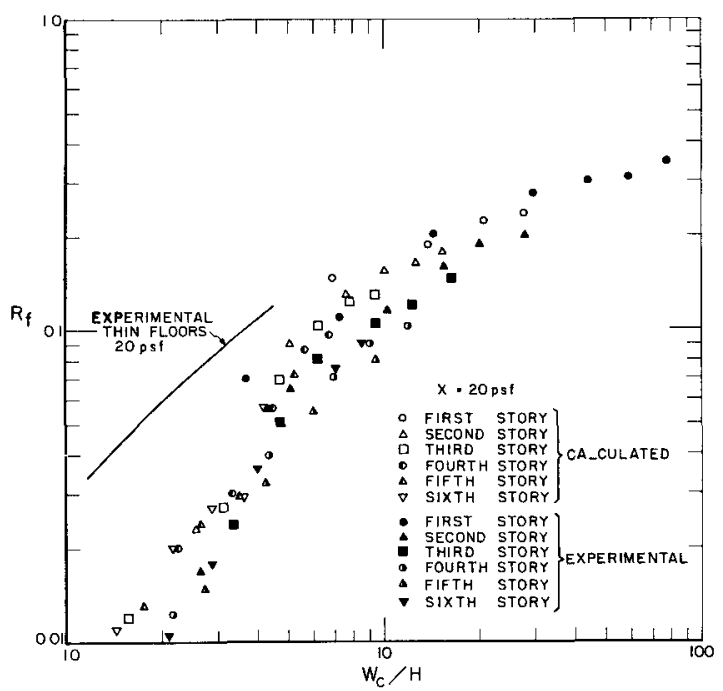

FIGURE 19 Reductıon factors for detectors at a height $\mathrm{H}_{\text {in }}$ butldings surrounded by rectangular source annult of width $\mathrm{W}_{\mathrm{c}}$ Wall thickness equals $20 \mathrm{psf}$, floor thickness equals $80 \mathrm{psf}$ 


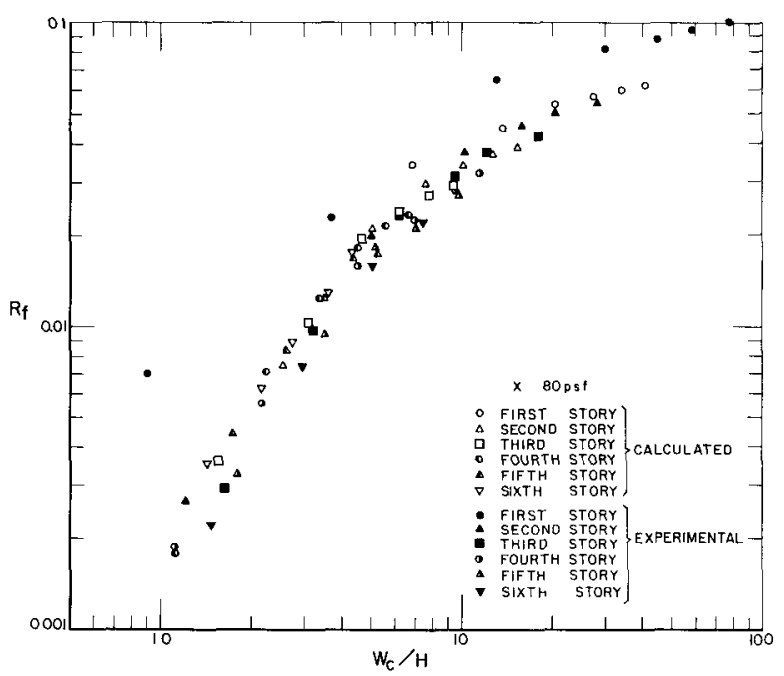

FIGURE 20 Reduction factors for detectors at a hetght $\mathrm{H}$ in bulldings surrounded by rectangular source annulı of width $\mathrm{W}_{\mathrm{c}}$ Wall thickness equals $80 \mathrm{psf}$, floor thuckness equals $80 \mathrm{psf}$

the detector is located. Such a large contribution from lower stories cannot be obtained from the calculations recommended in [2].

It should be noted that these experiments also yield data on finite rectangular source areas which do not run the entire length of the building. The present calculations do not explicitly provide rules for handling this situation, although many approaches have been suggested during the OCD courses at Fort Belvoir and other schools. When completed, the experiments should be analyzed to determine what rules can be inferred for handling such source areas.

An early experiment [13] performed at the Army Chemical Center by Technical Operations indicated that calculated dose rates may be too low by a factor of 2 in basements with no exposed walls. This discrepancy may be due in part to the inaccuracy of the schematization of figure 13 , as discussed in section 5 . The more recent experiments by Technical Operations on a six-story steel model tend to confirm this discrepancy. However, experimental dose rates in basements of scaled structures are complicated by the fact that the density of earth surrounding the basement is not properly scaled.

Experiments on complex office structures have yielded dose rates which do not agree with calculations better than a factor of 2 . For example, experiments [14] on the AEC Headquarters building in Germantown, Md., yielded dose rates which were a factor of two or three lower than calculations indicate. Due to the extremely heavy walls and floors in this building, the predominant contribution to the dose rate came from skyshine through the windows of the building. The situation was further complicated by the presence of an interior partition configuration similar to figure 18c. The experiment does not, therefore, indicate precisely what modifications should be made in the calculations.

\section{Conclusions}

The present engineering method gives detailed procedures for calculating the relative amount of protection from fallout radiation associated with a wide variety of shielding situations. Comparisons with experimental information show fairly good agreement for simple structures surrounded by an infinite plane source. The agreement is less satisfactory, however, for more complex structures and for source areas whose widths are comparable to the detector height. Nevertheless, the existence of the engineering method has suggested experiments whose results, in turn, may be expected to modify the engineering procedures.

I wish to thank L. V. Spencer of the National Bureau of Standards for his encouragement and advice in the development of the Engineering Method from his basic calculations, and Neal FitzSimons of the Office of Civil Defense, Department of Defense, for the many conversations which helped to develop and modify the calculational procedures. Without their help this work could not have been accomplished.

\section{References}

[1] L V Spencer, Structure sheldıng agannst fallout radiation from nurlear weapons, NBS Mono 42, June 1962 (U S Government Printing Office, Washington, D C )

[2] OCD Professional Manual PM 100-1, Design and review of structures for protection from fallout gamma radiation (In press)

[3] Fallout Shelter Surveys Guide for architects and engineers, OCD Report NP-10-2, Office of Civil Defense, Wash ington, D C

[4] L V Spencer and C Eisenhauer, Calculation of protection factors for the national fallout shelter survey (unpub lished)

[5] M Jakob, Heat Transfer, Vol II, John Wley \& Sons (1957)

[6] $\mathrm{F} \mathrm{S}$ Crawford, Jr, Solid angles subtended by a finite rectangular counter, Rev Sc1 Inst 24, 7 (1953)

[7] W B Boast, Illumınatıng Engıneerıng, Ist ed, McGraw Hıll Book Co, New York (1942)

[8] J H Hubbell, R L Bach, and J C Lamkın, Radıatıon field from a rectangular source, J Research, NBS, 64C, 2, Apr June 1960

[9] M A Schmoke and R E Rexroad, Attenuation of simulated radiation by the roof of a concrete blockhouse, NDLTR-6, August 1961, U S Army Chemical Center, Edge wood, Md

[10] M A Schmoke and R Rexroad, Attenuation of fallout radiation as a function of concrete blockhouse wall thickness, NDL-TR-43, October 1963, U S Army Chemical Center, Edgewood, Md

[11 ] J F Batter et al, The effect of limited strips of contamina tion on the dose rate in a multistory windowless bulding, TO-B 62-58, August 1962, Technical Operations, Inc, Burlıngton, Mass

[12 ] A W Starbird et al, The effect of interior partitions on the dose rate in a multistory windowless bulding, TO-B 63-6, January 1963, Technical Operatıons, Ine, Burlıng ton, Mass

[13 ] J F Batter and A W Starbird, Attenuation of cobalt 60 radiation by a simple structure with a basement, TO-B 61-38, July 1961, Techmical Operations, Inc , Burlington, Mass

[14] J F Batter, A Kaplan, and E T Clarke, An expenmental evaluation of the radiation protection afforded by a large modern concrete office building, May 1959, TO-B 59-5, Technical Operations, Inc, Burlington, Mass 


\section{Bibliography}

\section{Experimental Data}

1. J. F. Batter and A. W. Starbird, Attenuation of cobalt-60 by a simple structure with a basement, TO-B 61-38, Technical Operations, Inc., Burlington, Mass., July 1961.

2. A. W. Starbird, J. F. Batter, and H. A. Melhorn, Modeling techniques as applied to fallout simulation on residentialtype structures and some preliminary results, TO-B 61-35, Technical Operations, Inc., Burlington, Mass., July 1961.

3. J. F. Batter and A. W. Starbird, Attenuation of cobalt-60 radiation from a source distributed around a concrete blockhouse, TO-B 61-34, Technical Operations, Inc., Burlington, Mass., June 1961.

4. C. W. Terrell and A. J. Jerri, Radiation streaming in shelter entranceways, ARF-1158A01-5, Armour Research Foundation of Illinois Institute of Technology, Chicago, Ill., July 1961.

5. Z. Burson and H. Borella, Experimental evaluation of the radiation protection provided by the OCD region 3 demonstration shelter, CEP 60.6, Edgerton, Germeshausen, and Grier, Santa Barbara, Calif., April 1961.

6. Z. Burson, D. Parry, and H. Borella, Experimental evaluation of the fallout radiation protection afforded by a typical southwestern residential home, Edgerton, Germeshausen, and Grier, Inc., Santa Barbara, Calif., March 1961.

7. H. Borella, Z. Burson, and J. Jacovitch, Evaluation of the fallout protection afforded by Brookhaven National Laboratory Medical Research Center, CEP 60.1, Edgerton, Germeshausen, and Grier, Inc., Santa Barbara, Calif., Feb. 1961.

8. M. A. Schmoke and R. Rexroad, Attenuation of simulated fallout radiation by the roof of a concrete blockhouse, NDL-TR-6 Nuclear Defense Laboratory, Army Chemical Center, Edgewood, Md., Aug. 1961.

9. M. J. Schumchyk and H. J. Tiller, Ground penetrating radiation (Lip Contribution) in a foxhole from a fallout field simulated by Cobalt-60, NDL-TR-3, Nuclear Defense Laboratory, Army Chemical Center, Edgewood, Md., December 1960.

10. R. E. Rexroad and M. A. Schmoke, Scattered radiation and free field dose rates from distributed cobalt-60 and cesium137 sources, NDL-TR-2, Nuclear Defense Laboratory, Army Chemical Center, Edgewood, Md., Sept. 1960.

11. C. Eisenhauer, Scattering of cobalt-60 gamma radiation in air ducts, NBS Tech. Note 74, National Bureau of Standards, Washington, D.C., Oct. 1960.

12. C. Eisenhauer, Analysis of experiments on light residential structures with distributed cobalt-60 sources. (Unpublished.)

13. J. F. Batter, A. Kaplan, and E. T. Clarke, An experimental evaluation of the radiation protection afforded by a large modern concrete office building, TO-B 59-5, Technical Operations, Inc., Burlington, Mass., May 1959.

14. E. T. Clarke, J. F. Batter, and A. Kaplan, Measurement of attenuation in existing structures of radiation from simulated fallout, TO-B 59-4, Technical Operations, Inc., Burlington, Mass., April 1959.
15. J. A. Auxier et al., Experimental evaluation of the radiation protection afforded by residential structures against distributed sources, CEX-58.1, Atomic Energy Commission, Washington, D.C., Jan. 1959.

16. F. Titus, Penetration in concrete of gamma radiation from fallout. (Unpublished.)

17. C. E. Clifford, J. A. Carruthers, and J. R. Cunningham, Scattered gamma radiation from a simulated fallout field using cesium-137, Report DRCL-296, Defence Research Board, Ottawa, Canada, Jan. 1959.

18. J. R. Cunningham et al., Protection factors for houses using radioactive sources, Report DRCL-260, Defence Research Board, Ottawa, Canada, Nov. 1957.

19. R. T. Graveson, Radiation protection within a standard housing structure, Report NYO-4714, Nov. 1956.

20. A. G. McDonald, The penetration of gamma radiation from a uniform contamination into houses - A first report on some field trials, Report CD/SA-69 (Home Office), Jan. 1956.

21. N. G. Stewart et al., The shielding provided by a brick house against the gamma radiation from a uniformly deposited source. Experiments with cobalt-60, Report FWE-104, Oct. 1955. (Official Use Only.)

\section{Calculations}

22. L. V. Spencer, Structure shielding against fallout radiation from nuclear weapons, NBS Mono. 42, National Bureau of Standards, Washington, D.C., March 1962.

23. Fallout Shelter Surveys: Guide for Architects and Engineers, NP-10-2, Office of Civil and Defense Mobilization, Washington, D.C., May 1960

24. J. C. LeDoux and A. B. Chilton, Gamma ray streaming through two-legged rectangular ducts, Nucl. Sci. Eng. 11, Dec. 1961.

25. R. R. Putz and E. Kuykendall, A comparison of computed and experimentally observed intensity levels for various gamma radiation source distributions and shielding conditions in residential structures, University of California, Institute of Engineering Research, Feb. 1959.

26. R. R. Putz and A. Broido, A computation method for gamma configurations, Institute of Engineering Research, University of California, Dec. 1957.

27. A method for evaluating the protection afforded by buildings against fallout radiation (Draft), Executive Office of the President, Office of Civil and Defense Mobilization, Sept. 1957.

28. C. W. Malich and L. A. Beach, Radiation Protection afforded by barracks and underground shelters, Report NRL-5017, Naval Research Laboratory, Washington, D.C., Sept. 1957.

29. C. W. Malich and L. A. Beach, Fallout protection afforded by standard enlisted men's barracks, Report NRL -4886 , Naval Research Laboratory, Washington, D.C., March 1957.

30. Bureau of Yards and Docks, Studies in atomic defense engineering, Report NavDOCKS-P-290, Jan. 1957.

31. Home Office, Scottish Home Department, Assessment of the protection afforded by buildings against gamma radiation from fallout, May 1957. (Official Use Only.) 
Appendix A

Curves from Reference [1]

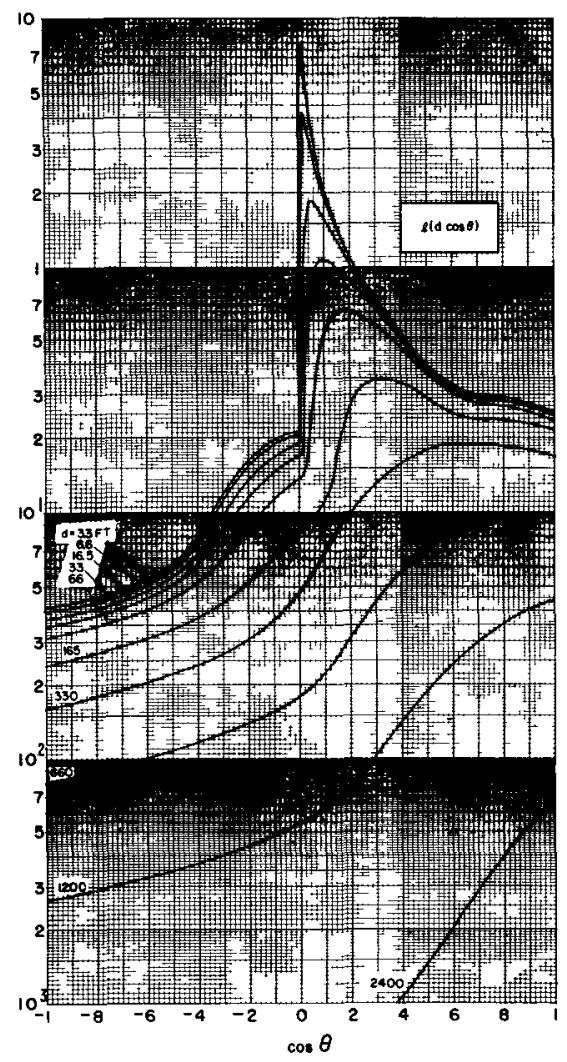

Figure Al Angular distribution of radia tıon at an tsotropic detector in atr above an infinite plane isotropic source

The angle $\theta$ is the angle between the direction of the radiation and the upward normal to the plane

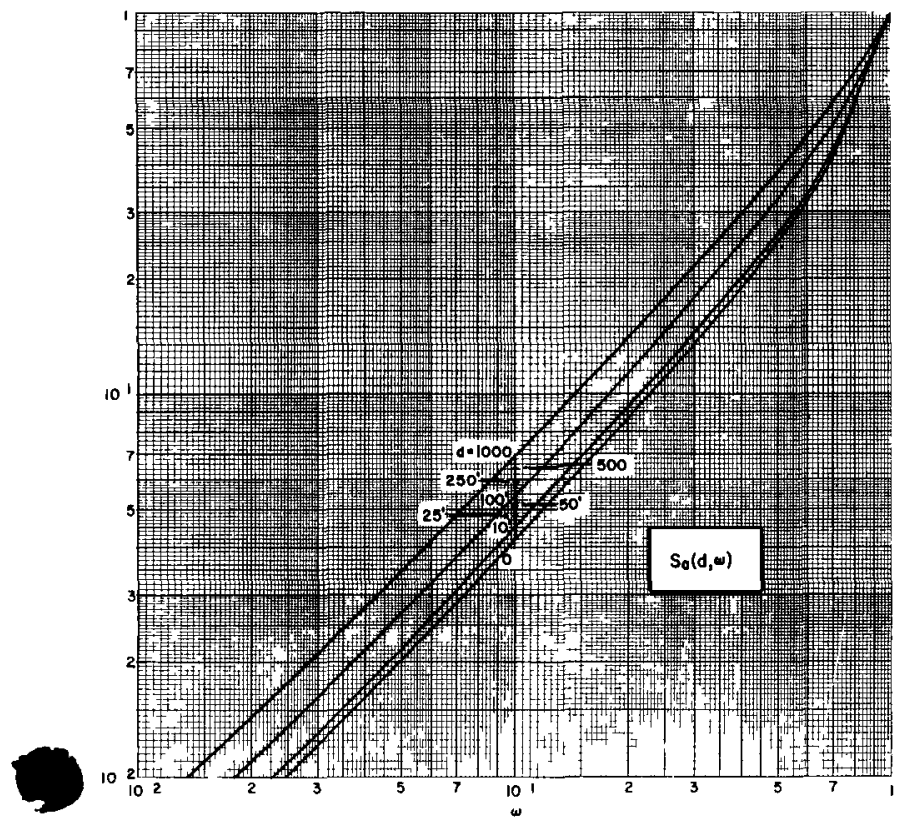

FIGURE A3 Intensity of shyshine radiatıon as a function of helght above an infinute plane usotroptc source

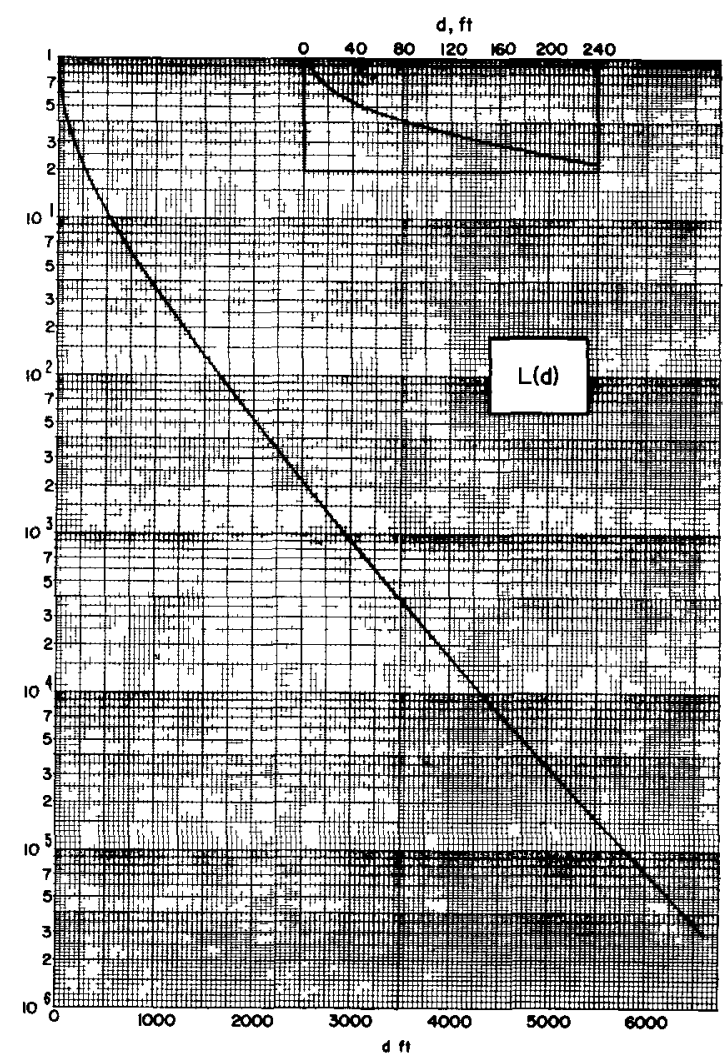

Figure A2 Dose rate as a function of height in aur above an infinute plane tsotropic source

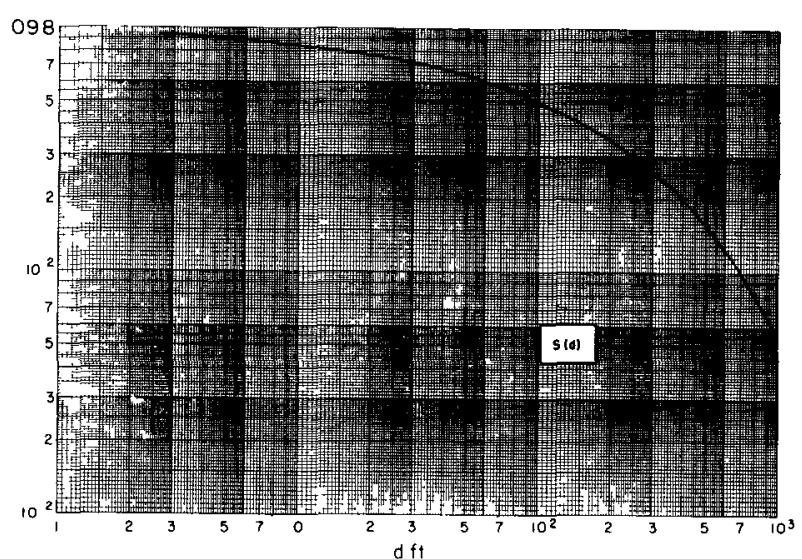

FIGURE A4 Detector response to skyshine as a function of the solud angle of the detector colltmator and the height above an infinite plane usotroptc source 


\section{Appendix B}

\section{Charts from Engineering Manual}

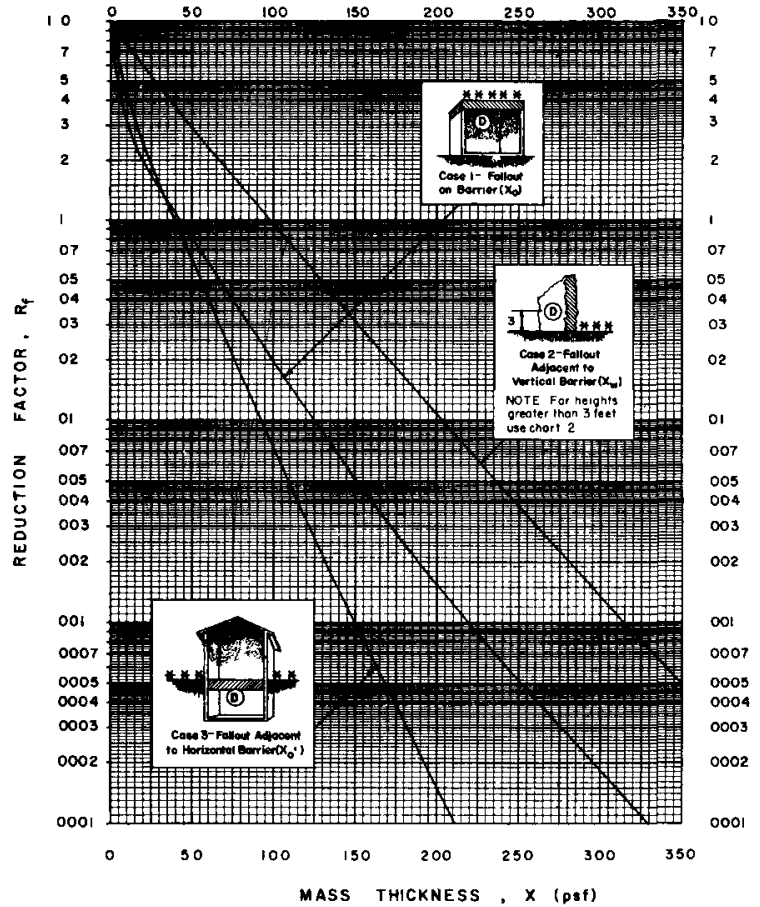

FIGURE Bl. Barrier shieldıng effects (plane sources) $\mathrm{B}_{\mathrm{w}}, \mathrm{B}_{\mathrm{w}}$, and $\mathrm{B}_{0}^{\prime}$.

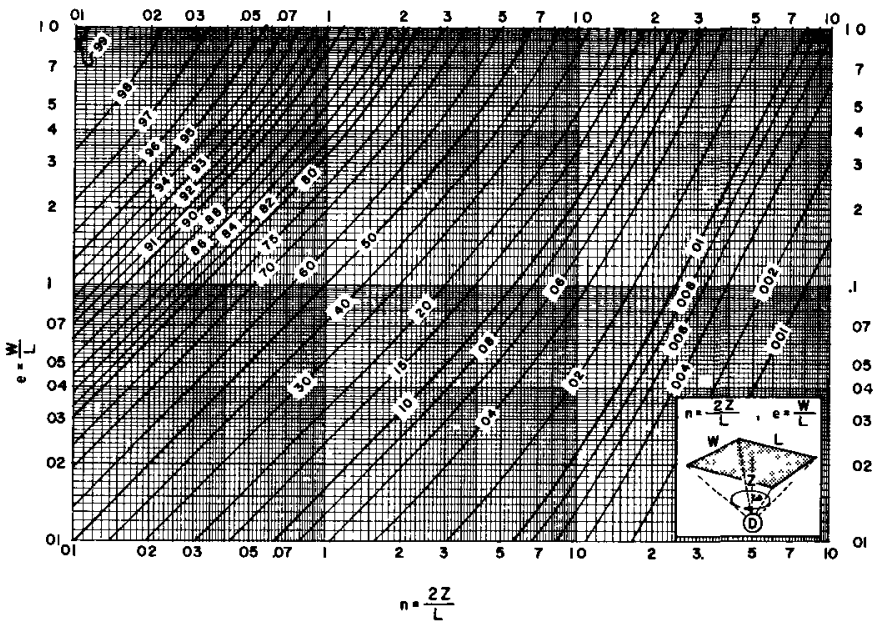

Figure B3. Solid angle fraction, $\omega$.

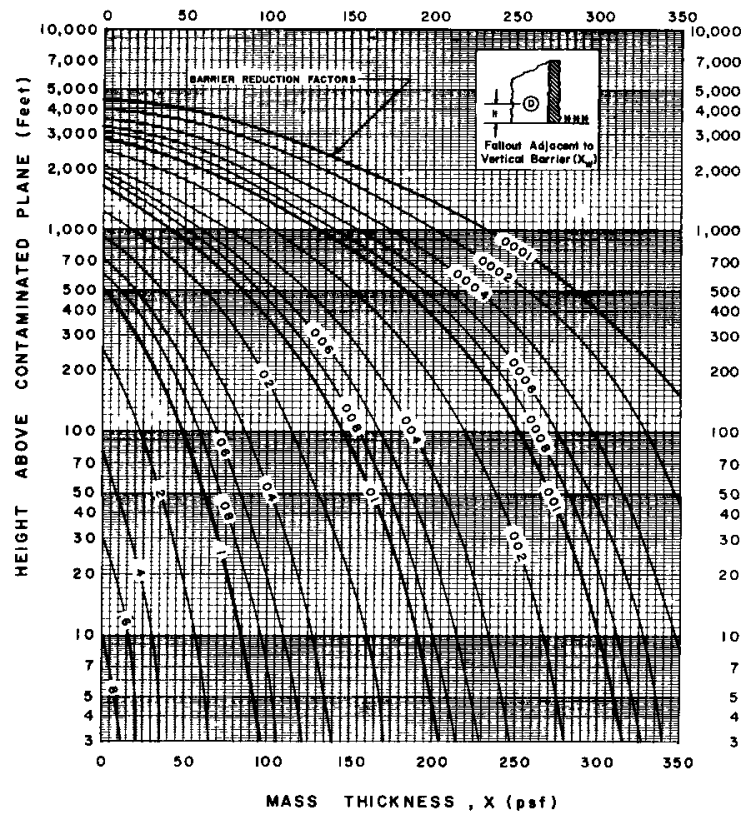

FIGURE B2. Wall barner shieldıng effects for various heights, $\mathbf{B}_{\mathbf{w}}$

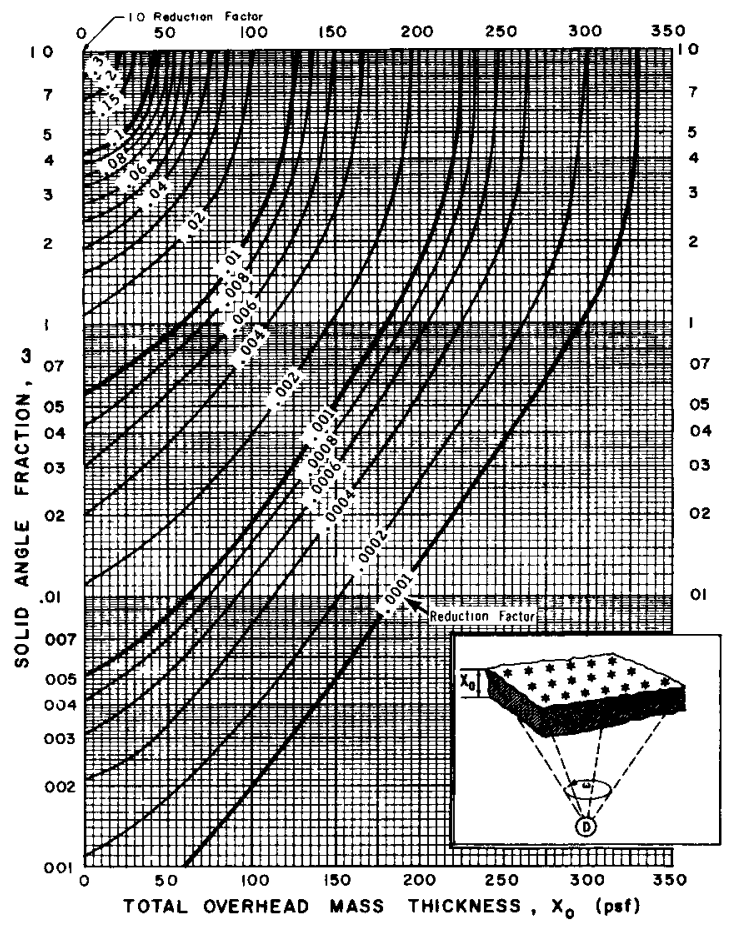

FIgUrE B4. Reduction factors for combined shielding effects, roof contribution, $\mathrm{C}_{0}$. 


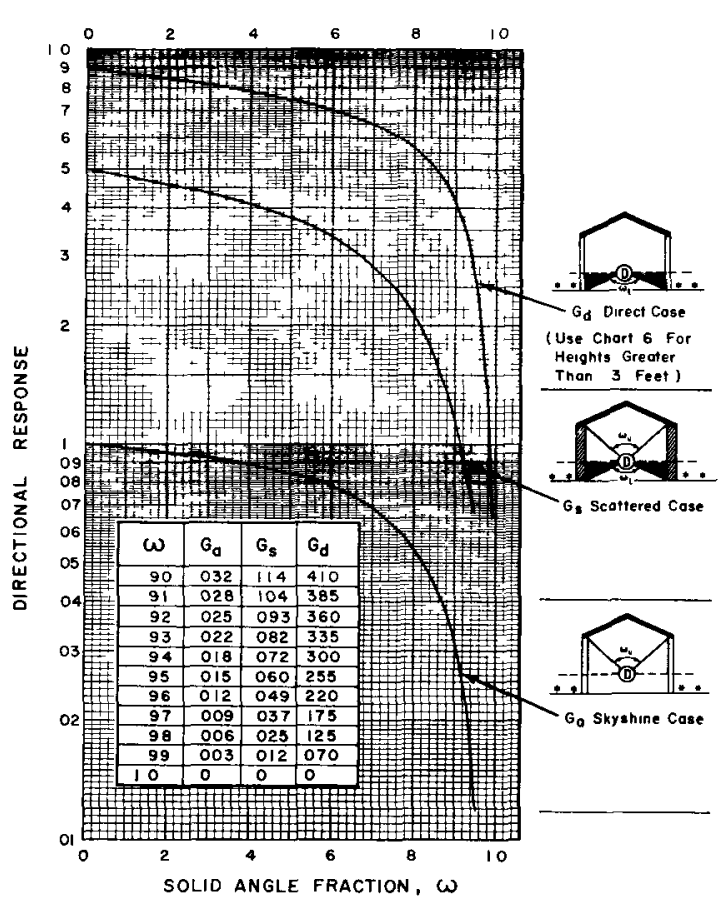

Figure B5. Directional responses, ground contribution, $G_{d}, G_{s}$ and $G_{a}$

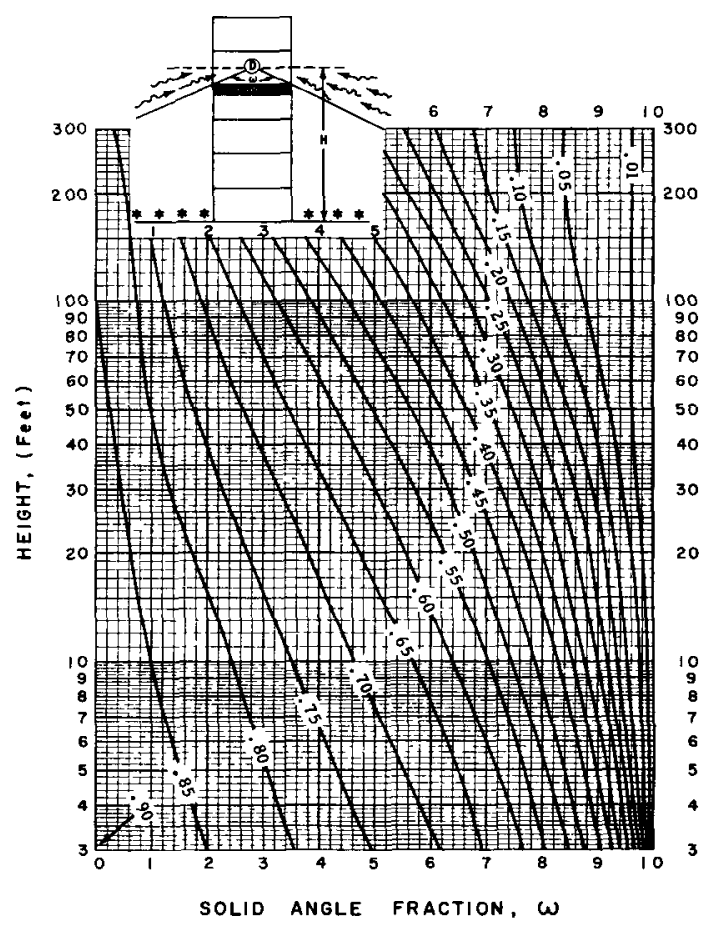

FIGURE B6. Directlonal responses for various heıghts, $\mathrm{G}_{\mathrm{d}}$

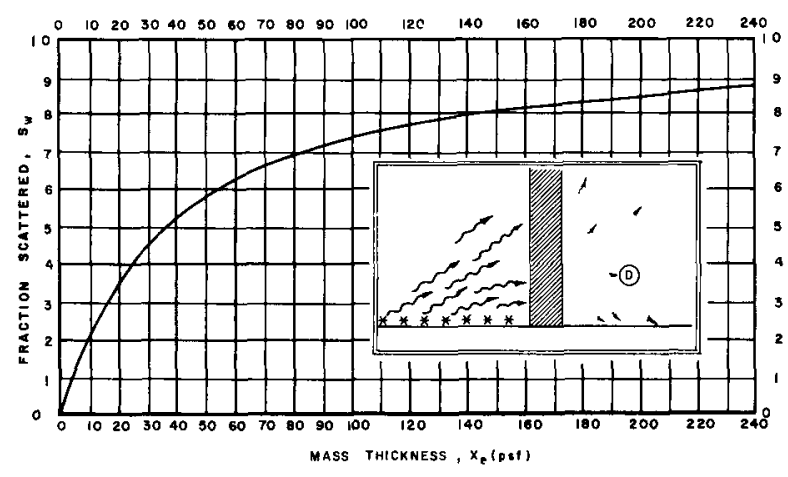

FIGURE B7. Fraction of emergent radiation scattered in wall barrler, $\mathrm{S}_{\mathrm{w}}$.

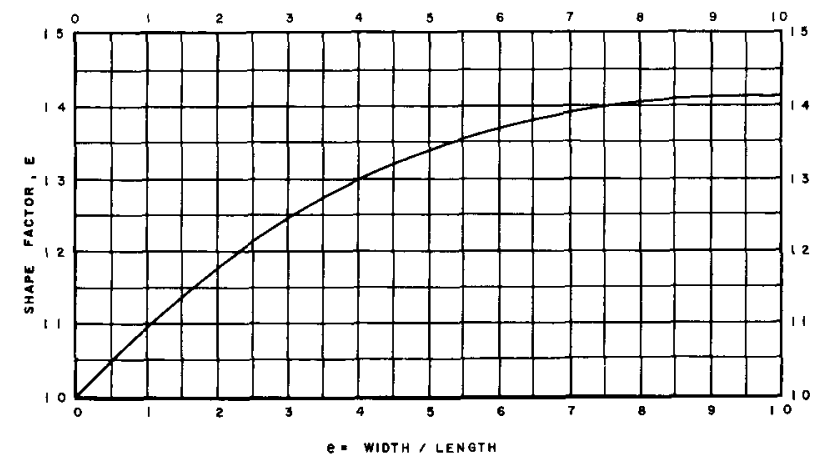

FIGURE B8. Shape factor for wall-scattered radiatıon, E. 


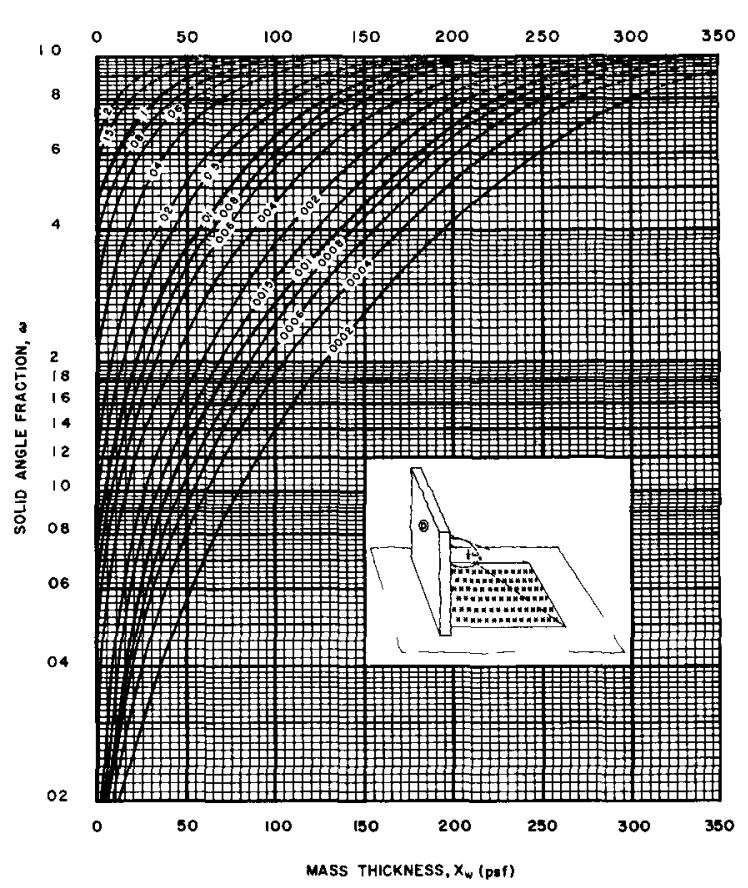

FIGURE B9. Barner reduction factors for wall-scattered radiation for limited strip of contamination

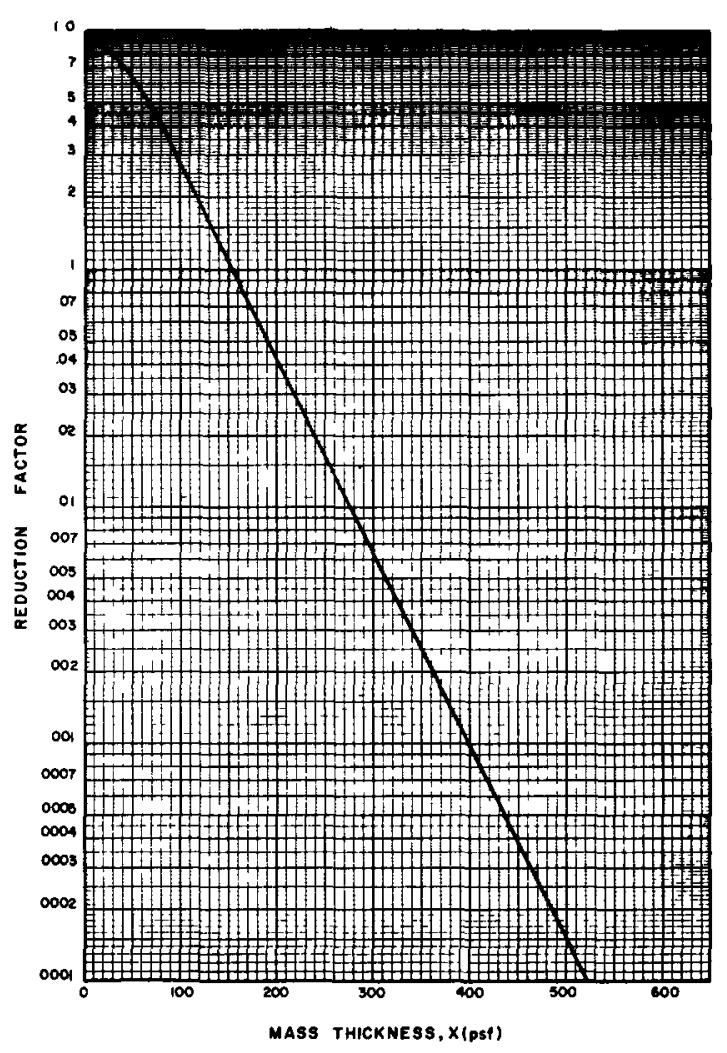

FIGURE B1l. Barrier shielding effects (point source).

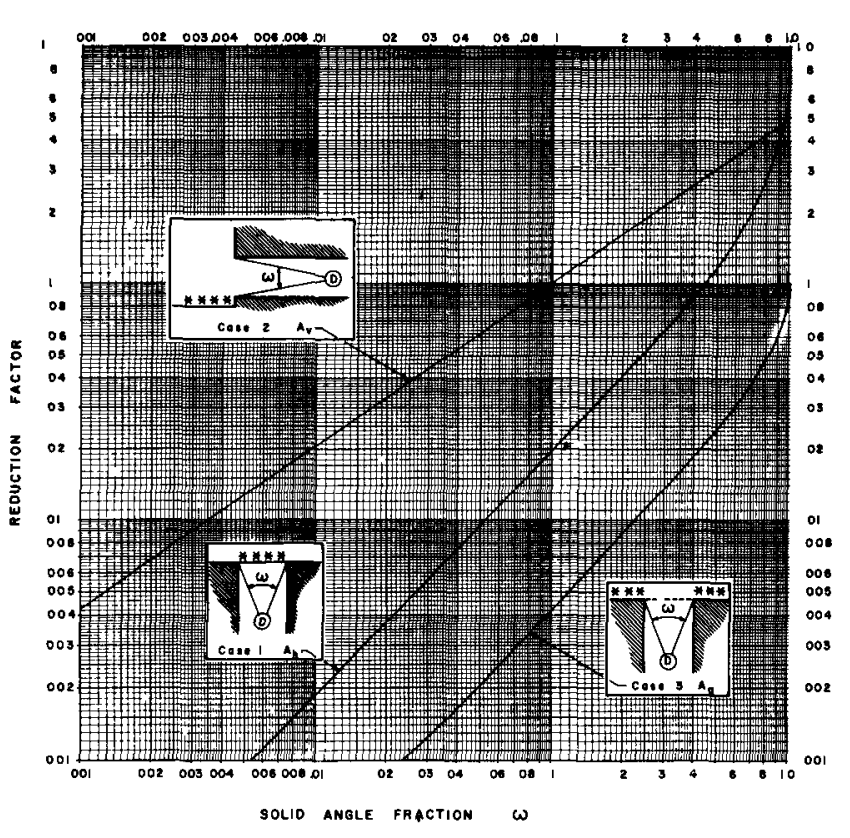

FIGURE B10. Reductıon factor for passageways and shafts.

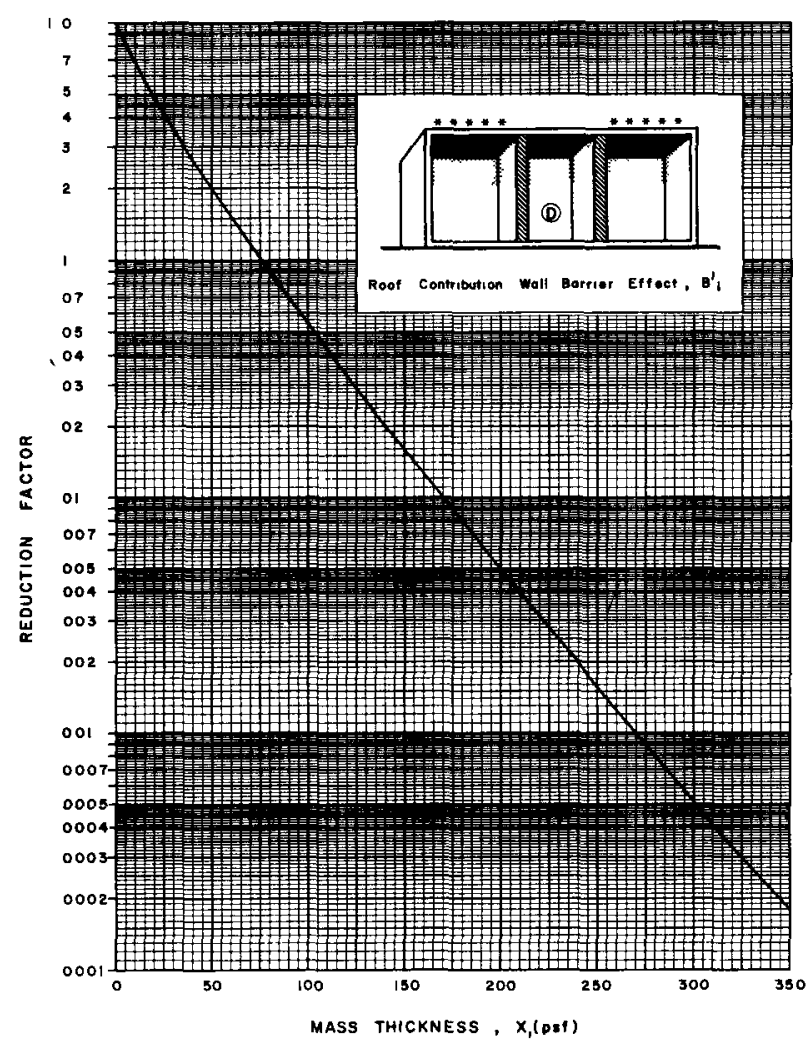

FIGURE B12. Roof contribution wall barrier effect. 